\title{
Evaluation of the K-Gill Propeller Vane
}

\author{
JOB W. VERKAIK \\ Department of Meteorology, Wageningen Agricultural University, the Netherlands
}

(Manuscript received 10 June 1997, in final form 1 October 1997)

\begin{abstract}
Dynamic properties of the K-Gill propeller vane ( $\mathrm{k}$ vane) are assessed from perturbation theory, wind tunnel, and field comparison experiments. Measurement errors for average wind speed are negligible. The dynamic response of the $\mathrm{k}$ vane can be described with a single response length that is the propeller's distance constant at a $45^{\circ}$ angle of attack. Measurement errors in longitudinal and vertical wind speed variances and the momentum flux due to propeller inertia can be described and corrected for as if the $\mathrm{k}$ vane were a simple first-order system. Standard spectra as well as spectra measured by the k vane itself can be used to calculate correction coefficients. In the latter case no information on atmospheric stability and boundary layer height is necessary. Transfer of lateral wind speed variance can be described as if the $\mathrm{k}$ vane were a damped harmonic oscillator. Measurement errors in lateral wind speed variance, however, are usually negligible because loss of high-frequency variance is compensated for by amplification of variance at the natural wavelength of the vane.

The propeller's distance constant and the vane's natural wavelength derived from the field comparison experiments are both smaller than those derived from the wind tunnel experiments. When the $\mathrm{k}$ vane is used at elevated levels $(z>20 \mathrm{~m})$, however, measurement errors become small and the exact values of the distance constant and the natural wavelength become insignificant. Parameters derived from the field experiments for the 35301 model are a response length of $2.9 \mathrm{~m}$, a natural wavelength of $7.8 \mathrm{~m}$, and a damping ratio of 0.49 . When the $\mathrm{k}$ vane is used at levels higher than $20 \mathrm{~m}$, the momentum flux lost due to instrument inertia will usually be less than $10 \%$. This means that the $\mathrm{k}$ vane is a suitable sensor for flux measurements on tall masts.
\end{abstract}

\section{Introduction}

The K-Gill propeller vane ( $\mathrm{k}$ vane) is an anemometer for measuring turbulent fluxes as well as mean flow properties. The $\mathrm{k}$ vane consists of two propellers-one oriented $45^{\circ}$ upward, the other $45^{\circ}$ downward - that are aligned into the mean wind direction by a vane. From the angular velocities of the propellers, horizontal and vertical wind speed components can be calculated. From the instantaneous values of the horizontal and vertical wind speed, momentum fluxes can be calculated using the eddy correlation method. Advantages of this design above its precursors, for example, the Gill UVW system (Gill 1975) or twin propeller-vane anemometers with a horizontal and a downward-looking propeller used earlier (Large and Pond 1981, 1982; Ataktürk and Katsaros 1987), are (a) its symmetry for up- and downdrafts, (b) the propellers are operating at moderate angles of attack, so the cosine response is well defined and no stalling of the propellers occurs, and (c) there is no need to align the instrument in the mean wind direction. Extension of the main shaft above the pivot of the vane and pro-

Corresponding author address: Job W. Verkaik, Department of Meteorology, Wageningen Agricultural University, Duivendaal 2, 6701 AP Wageningen, the Netherlands.

E-mail: job.verkaik@users.met.wau.nl peller mounting has improved symmetry even more. A similar design has been presented by Desjardins et al. (1986), but the k-vane anemometer in its present form was first introduced by Ataktürk and Katsaros (1989). So far the $\mathrm{k}$ vane has been used mainly to measure momentum fluxes over sea (Katsaros et al. 1987; Katsaros et al. 1993).

The $\mathrm{k}$ vanes discussed in this paper are used in a research project concerning turbulent fluxes of momentum and sensible heat in the atmospheric boundary layer over heterogeneous terrain (Verkaik 1997). Six k vanes have been installed at three levels $(20,100$, and $180 \mathrm{~m})$ at the 213-m meteorological mast of the Royal Netherlands Meteorological Institute (KNMI) at Cabauw (van Ulden and Wieringa 1996). In this project $\mathrm{k}$ vanes were preferred above, for example, sonic anemometers because the latter fail to operate in rain, wet snow, and heavy fog (Wyngaard 1981). Since our purpose was to operate continuously at Cabauw for at least a year, we could not consider using fair-weather instruments. Another operational advantage of the $\mathrm{k}$ vane is that it does not need to be pointed into the wind, as is the case with many sonics.

One copy of model 35301 and seven copies of a special model 35301DTX (manufactured by R. M. Young Co., United States) have been tested in the wind tunnel. The 35301 model has also been tested in a field com- 


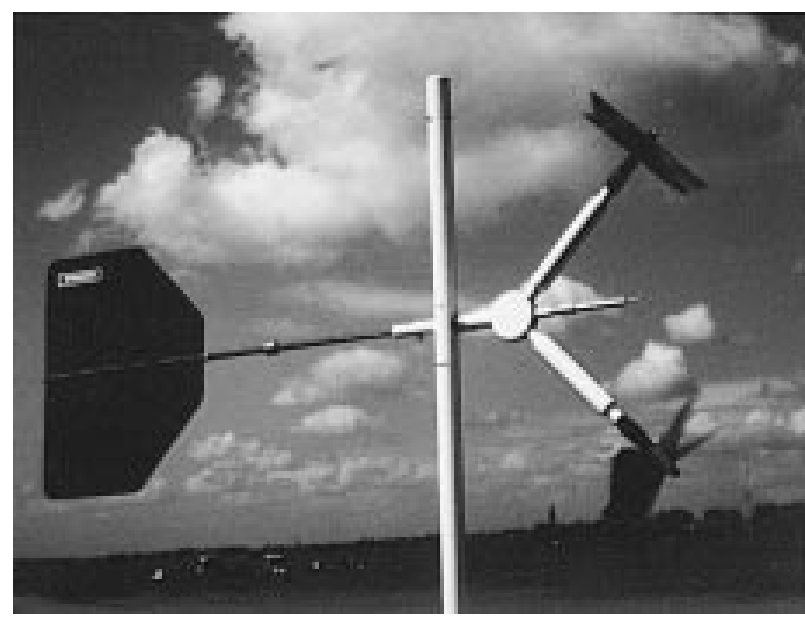

FIG. 1. Picture of the $\mathrm{k}$ vane.

parison experiment. The 35301 will be referred to as the "old" $\mathrm{k}$ vane and the 35301DTX as the "DTX."

The propellers and vane all have limited response times, so measurement errors can be expected when the $\mathrm{k}$ vane is exposed to high-frequency turbulence. In the present article the magnitude of the errors due to $\mathrm{k}$-vane inertia is assessed by perturbation theory, wind tunnel, and field experiments. Based on the spectral behavior of the $\mathrm{k}$ vane, simple methods are presented to correct for instrument inertia.

\section{Instrument description}

The total height of the $\mathrm{k}$ vane (see Fig. 1), including the base and extension tube, is $1.01 \mathrm{~m}$; the distance from the top of the base (diameter $0.16 \mathrm{~m}$ ) to the vane arm and propeller mounting is $0.60 \mathrm{~m}$. The diameter of the main shaft is $29 \mathrm{~mm}$, while the minimum distance from the main shaft to the propellers is $0.18 \mathrm{~m}$. The vane arm extends $0.40 \mathrm{~m}$ from the main shaft and the vane dimensions are $0.30 \mathrm{~m} \times 0.36 \mathrm{~m}$. Sturdy carbon fiber thermoplastic (CFT) propellers are used (diameter 0.20 $\mathrm{m}$, pitch $0.30 \mathrm{~m})$.

Model 35301DTX is a slightly different version of model 35301. The original shafts of the propellers and vane have been replaced by stronger ones, the mounting of the propellers has been modified to ensure a $90^{\circ}$ angle between the two propellers, and additional electric wires have been inserted to enable us to place thermocouple electronics in the extension tube above the pivot of the vane. We extended our $\mathrm{k}$ vanes with electrolytic level sensors (Inclinometer NB3, AE Sensors, the Netherlands) and thermocouples. The level sensor can be used to correct for alignment errors, and the thermocouple enables the $\mathrm{k}$ vane to measure sensible heat fluxes. We first intended to mount the level sensor at the beginning of the vane arm. This resulted in an erroneous reading of the level sensor since vane movements generate centripetal accelerations. A solution to this problem was found in mounting the level sensor inside the top of the extension tube on the axis of the main shaft.

\section{Interaction between propeller and vane dynamics}

Propellers and vanes have been used for many years in meteorology, and many articles have been devoted to their dynamical properties. Propeller dynamics (appendix A) and vane dynamics (appendix B) relevant to the $\mathrm{k}$ vane are briefly summarized. In this section the interaction between propeller and vane dynamics of the $\mathrm{k}$ vane will be discussed.

\section{a. K-vane response to a turbulent wind field}

An excellent analysis of the interaction of propeller and vane dynamics for a propeller vane in a turbulent wind field was given by Zhang (1988). From perturbation theory he found an expression for the over- or underspeeding of the propeller vane in terms of propeller and vane parameters and turbulent wind velocity spectra. In this section the analysis will be extended so that it can also be applied to the $\mathrm{k}$ vane. The overspeeding error, artificial vertical wind speed, and measured (co-)variances will be expressed in terms of the k vane's propeller and vane parameters and spectra of atmospheric turbulence.

The propeller response equations, Eqs. (A2) and (A3), can be written as

$$
\begin{aligned}
S & =c \omega \gamma_{R} R=\frac{c}{k}\left[V C(\psi) \cos \psi-\Delta u_{f}\right] \\
& =K\left[V C(\psi) \cos \psi-\Delta u_{f}\right],
\end{aligned}
$$

where $S$ is the output generated by the propeller and has dimension $[c] \times \mathrm{m} \mathrm{s}^{-1} \times \gamma_{R}$ and $R$ is the propeller's pitch factor and radius, and $\omega$ is its angular velocity. Here $V$ is the total wind vector; $C(\psi)$ is the cosine response function, where $\psi$ is the angle of attack; $\Delta u_{f}$ is the correction; and $K, k$, and $c$ are calibration constants. The mean angle of attack of the wind on the k-vane propellers is $\psi=45^{\circ}$. When linearized at $\psi=45^{\circ}$, Eq. (A4) yields

$$
C(\psi)=C_{0}-C_{1} \Delta \psi=0.83-0.3 \Delta \psi .
$$

The accuracy of Eq. (3.2) is better than $3 \%$ when $|\Delta \psi|$ $<15^{\circ}$. When $\bar{U}$ is along the positive $x$ axis, the angle of attack for the top propeller $\psi_{\text {top }}$ is given by

$$
\begin{aligned}
|T \| \mathrm{V}| \cos \psi_{\text {top }} & =\mathbf{T V}, \quad \mathbf{T}=\frac{1}{\sqrt{2}}\left(\begin{array}{c}
\cos \beta^{\prime} \\
\sin \beta^{\prime} \\
-1
\end{array}\right), \\
\mathbf{V} & =\left(\begin{array}{c}
U+u^{\prime} \\
v^{\prime} \\
w^{\prime}
\end{array}\right),
\end{aligned}
$$

where $\beta$ is the direction of the vane measured from the 
positive $x$ axis and $\mathbf{T}$ is a unit vector parallel to the propeller axis. Here $U$ is the average wind speed, and $u^{\prime}, v^{\prime}$, and $w^{\prime}$ are turbulent wind speed fluctuations with zero average. Retaining only terms up to the second order, the angle of attack for the top propeller in a turbulent wind field can be written as

$$
\begin{aligned}
\Delta \psi_{\mathrm{top}} & =\psi_{\mathrm{top}}-\pi / 4 \\
& =\frac{w^{\prime}}{U}-\frac{u^{\prime} w^{\prime}}{U^{2}}-\phi^{\prime} \beta^{\prime}+\frac{\beta^{\prime 2}+\phi^{\prime 2}}{2},
\end{aligned}
$$

where $\phi^{\prime}=v^{\prime} / U$. For the bottom propeller only the sign of $w^{\prime}$ changes. From Eqs. (3.3) and (3.4) the alongaxis wind component can be derived. Again, retaining only terms up to the second order this component equals

$$
\begin{aligned}
u_{\beta, \text { top }} & =|V| C\left(\psi_{\text {top }}\right) \cos \psi_{\text {top }}=C\left(\psi_{\text {top }}\right) \mathbf{T V} \\
& =\frac{C_{0} U}{\sqrt{2}}\left[1+\frac{u^{\prime}-a w^{\prime}}{U}+a \Lambda-\frac{C_{1}}{C_{0}}\left(\frac{\phi^{\prime 2}}{2}-\frac{w^{\prime 2}}{U^{2}}\right)\right],
\end{aligned}
$$

where $\Lambda=\phi^{\prime} \beta^{\prime}-\beta^{\prime 2} / 2$ and $a=1+C_{1} / C_{0}$. Averaging this equation results in

$$
\bar{u}_{\beta, \text { top }}=\frac{C_{0} U}{\sqrt{2}}\left(1+a \bar{\Lambda}-\frac{C_{1}}{C_{0}} \frac{\sigma_{\phi}^{2}}{2}+\frac{C_{1}}{C_{0}} \frac{\sigma_{w}^{2}}{U^{2}}\right),
$$

where $\bar{\Lambda}$ represents the " $v$ error." The positive correlation $\overline{\phi^{\prime} \beta^{\prime}}$, which may cause propeller vanes to overspeed due to vane motion, was overlooked by MacCready (1966). From Eqs. (3.5) and (3.6) it can be shown that

$$
\begin{aligned}
u_{\beta, \mathrm{top}}^{\prime}= & \frac{u_{\beta, \mathrm{top}}-\bar{u}_{\beta, \mathrm{top}}}{\bar{u}_{\beta, \mathrm{top}}} \\
= & \frac{u^{\prime}-a w^{\prime}}{U}+a(\Lambda-\bar{\Lambda})-\frac{C_{1}}{C_{0}} \\
& \times\left(\frac{\phi^{\prime 2}-\sigma_{\phi}^{2}}{2}-\frac{w^{\prime 2}-\sigma_{w}^{2}}{U^{2}}\right) .
\end{aligned}
$$

Zhang (1988) derived the following expressions for the propeller response $S$ :

$$
\begin{aligned}
\frac{D}{u_{\beta}} \frac{d S}{d t} & =K\left(u_{\beta}-\Delta u_{f}\right)-S, \\
S & =S_{\beta}\left(1+s^{\prime}\right)=K\left(\overline{u_{\beta}}-\Delta u_{f}\right)\left(1+\mathrm{s}^{\prime}\right), \\
\tau \frac{d s^{\prime}}{d t}+s^{\prime} & =(1+\epsilon) u_{\beta}^{\prime}-s^{\prime} u_{\beta}^{\prime}+(1+\epsilon) u_{\beta}^{\prime 2},
\end{aligned}
$$

where $\epsilon=\Delta u_{f} / \overline{u_{\beta}}$ and $\tau=D / \overline{u_{\beta}}$. Here $D$ is the propeller's distance constant. Inserting (3.7) in (3.10), neglecting $\epsilon$, and retaining only terms up the second order results in

$$
\begin{aligned}
\tau \frac{d s_{\mathrm{top}}^{\prime}}{d t}+s_{\mathrm{top}}^{\prime} \\
=\left(1-s_{\mathrm{top}}^{\prime}+\frac{u^{\prime}-a w}{U}\right)\left(\frac{u^{\prime}-a w^{\prime}}{U}\right)+a(\Lambda-\bar{\Lambda}) \\
\quad-\frac{C_{1}}{C_{0}} \frac{\phi^{\prime 2}-\sigma_{\phi}^{2}}{2}+\frac{C_{1}}{C_{0}} \frac{w^{\prime 2}-\sigma_{w}^{2}}{U^{2}} .
\end{aligned}
$$

For the bottom propeller again only the sign of $w^{\prime}$ changes. Averaging Eq. (3.11) yields correlations between $s^{\prime}$ and $u^{\prime}$ and between $s^{\prime}$ and $w^{\prime}$. Evaluation of $s^{\prime} u^{\prime}$ and $s^{\prime} w^{\prime}$ starts with the approximation of Eq. (3.11), using first-order terms only:

$$
\tau d s^{\prime} / d t+s^{\prime}=u^{\prime} / U-a w^{\prime} / U .
$$

Following the same procedure Busch and Kristensen (1976) used for the determination of cup anemometer overspeeding, we find

$$
\begin{aligned}
& \overline{s^{\prime} u^{\prime}}{ }_{\text {top }} \\
& \quad=\frac{\sigma_{u}^{2}}{U} \int_{0}^{\infty} \frac{S_{u}(\omega)}{1+(\omega \tau)^{2}} d \omega-a \frac{\overline{u^{\prime} w^{\prime}}}{U} \int_{0}^{\infty} \frac{C_{u w}(\omega)}{1+(\omega \tau)^{2}} d \omega,
\end{aligned}
$$

and

$$
\begin{aligned}
& \overline{s^{\prime} w^{\prime}}{ }_{\text {top }} \\
& \quad=\frac{\overline{u^{\prime} w^{\prime}}}{U} \int_{0}^{\infty} \frac{C_{u w}(\omega)}{1+(\omega \tau)^{2}} d \omega-a \frac{\sigma_{w}^{2}}{U} \int_{0}^{\infty} \frac{S_{w}(\omega)}{1+(\omega \tau)^{2}} d \omega .
\end{aligned}
$$

Here $S_{u}$ and $S_{w}$ are the variance spectra of $u^{\prime}$ and $w^{\prime}$, and $C_{u w}$ is the cospectrum of $u^{\prime} w^{\prime}$. The spectra are normalized so that $\int_{0}^{\infty} S_{u, w}(\omega) d \omega=\int_{0}^{\infty} C_{u w}(\omega) d \omega=1$. Again for the bottom propeller only, the sign of the second term in Eqs. (3.13) and (3.14) changes. The following expressions can now be derived from Eqs. (3.11), (3.13), and (3.14):

$$
\begin{aligned}
{\overline{s^{\prime}}}_{\mathrm{btm}}+{\overline{s^{\prime}}}_{\text {top }}= & 2 \frac{\sigma_{u}^{2}}{U^{2}}\left(1-\int_{0}^{\infty} \frac{S_{u}(\omega) d \omega}{1+(\omega \tau)^{2}}\right) \\
& +2 a^{2} \frac{\sigma_{w}^{2}}{U^{2}}\left(1-\int_{0}^{\infty} \frac{S_{w}(\omega) d \omega}{1+(\omega \tau)^{2}}\right), \\
\overline{\left(s_{\mathrm{btm}}^{\prime}-s_{\mathrm{top}}^{\prime}\right)^{2}}= & 4 a^{2} \frac{\sigma_{w}^{2}}{U^{2}} \int_{0}^{\infty} \frac{S_{w}(\omega) d \omega}{1+\tau^{2} \omega^{2}} .
\end{aligned}
$$

Instead of averaging the total horizontal wind speed and wind direction, the instantaneous horizontal wind speed and direction are decomposed in eastward and northward wind components. Rotation of $\overline{v^{\prime}}$ and $\overline{w^{\prime}}$ to zero can be done after a measurement interval has been completed. So the wind speed in the $x$ direction indicated by the $\mathrm{k}$ vane is given by 


$$
U_{m}=U(1+\delta)=\cos \beta^{\prime} \cos \Delta \psi^{\infty}\left|V_{m}\right|,
$$

where $\Delta \psi^{\circ}$ is the measured inclination of the wind vector and $\delta$ is the overspeeding error. Here $\left|V_{m}\right|$ is the measured total wind speed,

$V_{m}^{2}=\left(\frac{S_{\mathrm{top}}}{K\left(C_{0}-C_{1} \Delta \psi^{\infty}\right)}\right)^{2}+\left(\frac{S_{\mathrm{btm}}}{K\left(C_{0}+C_{1} \Delta \psi^{\infty}\right)}\right)^{2}$.

The inclination of the wind vector $\Delta \psi^{\infty}$ is calculated from measured $s_{\mathrm{btm}}^{\prime}$ and $s_{\mathrm{top}}^{\prime}$. To correct the measured responses for cosine response, $\psi_{\mathrm{btm}}$ and $\psi_{\text {top }}$ must be known. Using an iterative process described by Ataktürk and Katsaros (1989) $\Delta \psi^{\infty}$ can be solved. A necessary assumption to solve $\Delta \psi^{\circ}$ is $\Delta \psi_{\mathrm{btm}}=-\Delta \psi_{\text {top }}$ or $\psi_{\text {top }}+$ $\psi_{\mathrm{btm}}=\pi / 2$, which is only true when $\phi^{\prime}=\beta^{\prime}$. From Eq. (3.4) note that generally $\psi_{\text {top }}+\psi_{\text {btm }}>\pi / 2$. This will result in two different errors: The total wind is not correctly decomposed in vertical and horizontal parts, and the cosine response correction is applied using a smaller angle of attack, resulting in an overestimation of the wind speed.

From a first guess of $\Delta \psi^{(1)}(=0)$ the next step of the iteration yields $\Delta \psi^{(2)}$ :

$$
\tan \left(\frac{\pi}{4}+\Delta \psi^{(2)}\right)=\frac{s_{\mathrm{btm}}^{\prime}}{1+C_{1} / C_{0} \Delta \psi^{(1)}} \frac{1-C_{1} / C_{0} \Delta \psi^{(1)}}{s_{\mathrm{top}}^{\prime}} .
$$

Retaining only terms of the first order, this can be simplified to

$$
\Delta \psi^{(2)}=\frac{1}{2}\left(s_{\mathrm{btm}}^{\prime}-s_{\mathrm{top}}^{\prime}\right)-\frac{C_{1}}{C_{0}} \Delta \psi^{(1)} .
$$

The result of the iterative process will be

$\Delta \psi^{\infty}=\frac{1}{2}\left(s_{\mathrm{btm}}^{\prime}-s_{\mathrm{top}}^{\prime}\right) \sum_{n=0}^{\infty}\left(-\frac{C_{1}}{C_{0}}\right)^{n}=\frac{s_{\mathrm{btm}}^{\prime}-s_{\mathrm{top}}^{\prime}}{2 a}$.

For fast propeller response $(\omega \tau \ll 1)$ this equation yields $\Delta \psi^{\infty}=w^{\prime} / U$.

From Eqs. (3.6), (3.9), (3.18), and (3.21), $V_{m}$ can now be calculated:

$$
\begin{aligned}
\frac{V_{m}}{U}= & 1+\frac{s_{\mathrm{btm}}^{\prime}+s_{\mathrm{top}}^{\prime}}{2}-\frac{\left(s_{\mathrm{btm}}^{\prime}+s_{\mathrm{top}}^{\prime}\right)^{2}}{8} \\
& +\frac{1}{4}\left(s_{\mathrm{btm}}^{\prime}-\frac{C_{1}}{C_{0}} \Delta \psi^{\infty}\right)^{2}+\frac{1}{4}\left(s_{\mathrm{top}}^{\prime}+\frac{C_{1}}{C_{0}} \Delta \psi^{\infty}\right)^{2} \\
& +\frac{C_{1}}{2 C_{0}} s_{\mathrm{top}}^{\prime} \Delta \psi^{\infty}-\frac{C_{1}}{2 C_{0}} s_{\mathrm{btm}}^{\prime} \Delta \psi^{\infty}+\frac{C_{1}}{C_{0}} \frac{\sigma_{w}^{2}}{U^{2}}+\frac{C_{1}^{2}}{C_{0}^{2}} \frac{\sigma_{w}^{2}}{U^{2}} \\
& +a \bar{\Lambda}-\frac{C_{1}}{C_{0}} \frac{\sigma_{\phi}^{2}}{2} .
\end{aligned}
$$

Now $\delta$ can be calculated from Eqs. (3.17) and (3.22):

$$
\begin{aligned}
\delta= & \frac{s_{\mathrm{btm}}^{\prime}+s_{\mathrm{top}}^{\prime}}{2}+\frac{C_{1}}{C_{0}}\left(\frac{\sigma_{w}^{2}}{U}-\frac{\left(s_{\mathrm{btm}}^{\prime}-s_{\mathrm{top}}^{\prime}\right)^{2}}{4 a^{2}}\right) \\
& +a \bar{\Lambda}+\frac{C_{1}}{C_{0}} \frac{\sigma_{\phi}^{2}}{2}-\frac{\beta^{\prime 2}}{2} .
\end{aligned}
$$

Averaging this equation yields [using Eqs. (3.15) and (3.16)]

$$
\begin{aligned}
\bar{\delta}= & \frac{\sigma_{u}^{2}}{U^{2}}\left(1-\int_{0}^{\infty} \frac{S_{u}(\omega) d \omega}{1+(\omega \tau)^{2}}\right)+\left(a^{2}+\frac{C_{1}}{C_{0}}\right) \\
& \times \frac{\sigma_{w}^{2}}{U^{2}}\left(1-\int_{0}^{\infty} \frac{S_{w}(\omega) d \omega}{1+(\omega \tau)^{2}}\right)-\frac{C_{1}}{2 C_{0}} \sigma_{\phi}^{2} \\
& \times\left(1-\int_{0}^{\infty} \frac{1-2 a /(a-1)\left(\omega / \omega_{0}\right)^{2}}{\left(1-\omega^{2} / \omega_{0}^{2}\right)^{2}+4 \zeta^{2} \omega^{2} / \omega_{0}^{2}} S_{v}(\omega) d \omega\right) .
\end{aligned}
$$

The first term and the first part of the second term in Eq. (3.24) represent the propeller overspeeding; the second part of the second term is the result of the discrepancy between the measured and real (instantaneous) inclination angle. The real wind inclination is usually larger than the measured inclination. Inclination of the wind vector will reduce the angle of attack on one propeller while increasing the angle of attack on the other. However, the increase in response of the former is larger than the decrease in response of the latter. So, the net effect will lead to an increase in the jointly measured horizontal wind speed. The correction to the total wind speed, which is applied using the measured inclination angle, is largest at zero inclination. When the inclination angle is underestimated, propeller responses are corrected using a too-large correction, resulting in an overspeeding error. The third term in Eq. (3.24) represents the total $v$ error. It is smaller than that derived by Zhang (1988) since decomposition of wind speed into horizontal components is done before averaging. In case of an infinitely fast propeller vane response, so that $\omega \tau \ll$ 1 and $\beta^{\prime}=\phi^{\prime}, \delta$ equals zero.

For the measured vertical wind speed, Eq. (3.17) changes to

$$
\frac{w_{m}}{U}=\eta=\sin \Delta \psi^{\infty} \frac{\left|V_{m}\right|}{U}=\frac{s_{\mathrm{btm}}^{\prime}-s_{\mathrm{top}}^{\prime}}{2 a}+\frac{s_{\mathrm{btm}}^{\prime 2}-s_{\mathrm{top}}^{\prime 2}}{4 a},
$$

which yields after averaging

$$
\bar{\eta}=\frac{\overline{u^{\prime} w^{\prime}}}{U^{2}}\left(1-\int_{0}^{\infty} \frac{C_{u w}(\omega) d \omega}{1+(\omega \tau)^{2}}\right) .
$$

Note that $\eta$ is always negative. Using the measured momentum flux we can write

$$
\begin{aligned}
-u_{* m}^{2} / U^{2} & =\overline{\left(U_{m}-\overline{U_{m}}\right)\left(w_{m}-\overline{w_{m}}\right)} / U^{2} \\
& =\overline{\delta \eta}-\bar{\delta} \bar{\eta} .
\end{aligned}
$$


Evaluating this equation, all terms higher than the first in $\delta$ and $\eta$ can be neglected since no spectra higher than the second order are available. Equation (3.27) then yields

$$
\frac{-u_{* m}^{2}}{U^{2}}=\frac{\overline{u^{\prime} w^{\prime}}}{U^{2}} \int_{0}^{\infty} \frac{C_{u w}(\omega) d \omega}{1+(\omega \tau)^{2}},
$$

which is the regular first-order transfer function. In the same way the measured longitudinal and vertical wind speed variance can be expressed as

$$
\frac{\sigma_{u m}^{2}}{U^{2}}=\overline{\delta^{2}}-\bar{\delta}^{2}=\frac{\sigma_{u}^{2}}{U^{2}} \int_{0}^{\infty} \frac{S_{u}(\omega) d \omega}{1+(\omega \tau)^{2}}
$$

and

$$
\frac{\sigma_{w m}^{2}}{U^{2}}=\overline{\eta^{2}}-\bar{\eta}^{2}=\frac{\sigma_{w}^{2}}{U^{2}} \int_{0}^{\infty} \frac{S_{u}(\omega) d \omega}{1+(\omega \tau)^{2}} .
$$

So for all variances the regular first-order transfer function applies with a response length equal to the distance constant of the propeller at $45^{\circ}$ angle of attack. The transfer of lateral wind speed variance is given by Eq. (B4).

\section{b. Gyroscopic stability propellers}

Wieringa (1967) and Busch et al. (1980) mention the possibility of the angular momentum of the propeller $(L)$ to be responsible for the gyroscopic stability of the vane. This applies, however, only to propeller vanes that can swivel in two directions, which are called trivanes. For vanes that can rotate only about a single axis, gyroscopic stability of propellers is not possible, as will be explained below.

Vane movements will alter the direction of $L$, so $d L /$ $d t$ is in the horizontal plane. Therefore, forces that are induced by azimuthal movements act in the elevation direction on the propeller axis. The propeller vane or $\mathrm{k}$-vane axis cannot be elevated. Azimuthal movements of trivanes, however, can change elevation angles and vice versa.

The only way gyroscopic stability could possibly influence vane dynamics is by increased friction, as a result of the torque, on the bearings that support the vane. However, these torques will be small compared to other torques on the vane. For $U=12.5 \mathrm{~m} \mathrm{~s}^{-1}$ the $\mathrm{k}$-vane propellers will rotate at $150 \mathrm{rad} \mathrm{s}^{-1}$. To assess the moment of inertia of the propeller, a tiny load has been attached to the tip of one of the blades and then the period of oscillation has been determined. The moment of inertia found this way equals $8.6 \times 10^{-5} \mathrm{~kg}$ $\mathrm{m}^{2}$. The angular momentum of the two propellers $\mathbf{L}_{\text {prop } 1}$ $+\mathbf{L}_{\text {prop2 }}=1.8 \times 10^{-2} \mathrm{~kg} \mathrm{~m}^{2} \mathrm{~s}^{-1}$. Typical angular velocity of the vane equals $0.75 \mathrm{rad} \mathrm{s}^{-1}$. So the torque on the propeller axis is $1.4 \times 10^{-2} \mathrm{~N} \mathrm{~m}$. The torque on the vane blade at $3^{\circ}$ from equilibrium equals $0.4 \mathrm{~N} \mathrm{~m}$ at this wind speed. So, in general, torques from gyroscopic stability are very small compared to torques on the vane

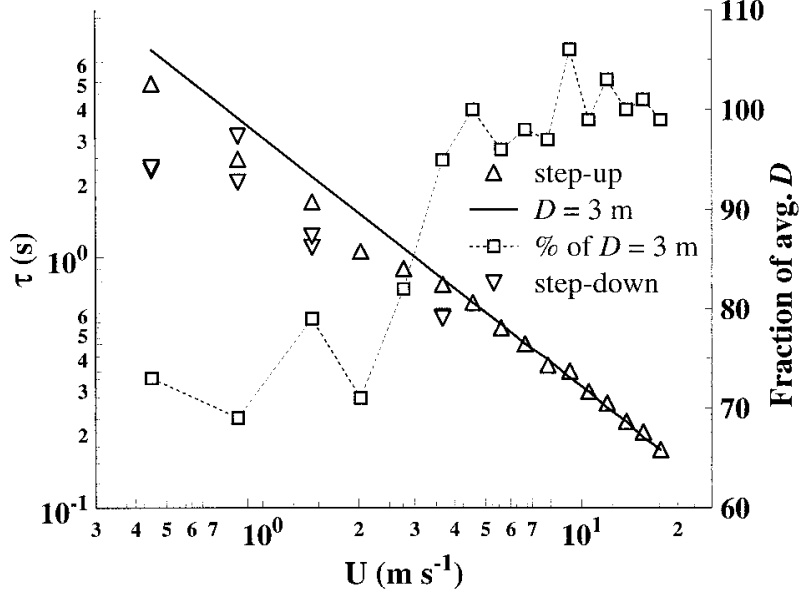

FIG. 2. Dependence of $D$ on $U_{\infty}$.

blade; however, those torques are perpendicular. In the case of the $\mathrm{k}$ vane, the torque by drag on the extension tube is probably much larger.

\section{Wind tunnel experiments}

\section{a. Propeller tests}

The author has tested the CFT propellers (model 08254) in the wind tunnel of the Department of Meteorology of the Wageningen Agricultural University (WAU). This wind tunnel has an octagonal working section with a length of $0.4 \mathrm{~m}$ and a radius of $0.2 \mathrm{~m}$ (Monna 1983). So it is just large enough to do propeller tests (radius $0.1 \mathrm{~m}$ ). Step changes in wind speed were used to determine the propeller's response length. To perform step-down tests without significantly disturbing the mean flow, a fine cotton wire was wound round the propeller shaft. By pulling the wire the propeller was sped up like a top. This way propeller velocities of 4 $\mathrm{m} \mathrm{s}^{-1}$ could be achieved. When the propeller is speeded up in reverse direction, the same procedure can be used for step-up tests. Equation (A5) has been fitted to the measured response to determine the response time. Only the tail of the response curve, after $60 \%$ adaption, has been used.

Results are summarized in Fig. 2. The response time $\tau$ is plotted as function of $U_{\infty}$. The solid line corresponds to $\tau=D / U_{\infty}$ with $D=3.0 \mathrm{~m}$, the overall average. From this figure it is clear that for small $U_{\infty}$ 's, $\tau$ is less than would be expected from $D=3 \mathrm{~m}$ for both the step-up and step-down tests. The dashed curve gives the relative decrease of $D$ for step-up tests in percentages. For $U_{\infty}$ $<4 \mathrm{~m} \mathrm{~s}^{-1} D$ decreases with $30 \%$, so at low wind speeds the propeller responds quicker.

Response times for step-down tests seem to be smaller than for step-up tests; $D$ for step-down tests equals about half the value of $D$ for step-up tests when $U<2 \mathrm{~m} \mathrm{~s}^{-1}$. A possible explanation is the friction of the bearings. This will increase the deceleration of the propeller and 
TABLE 1. Model 35301 vane properties from wind tunnel tests.

\begin{tabular}{|c|c|c|c|c|c|c|c|}
\hline \multirow[b]{2}{*}{ Veer } & \multirow[b]{2}{*}{$\begin{array}{l}\lambda_{n}(\mathrm{~m}) \\
\zeta\end{array}$} & \multicolumn{2}{|c|}{ Overshoot } & \multicolumn{2}{|c|}{$\begin{array}{c}\text { Least squares } \\
\text { method }\end{array}$} & \multicolumn{2}{|c|}{ Both } \\
\hline & & $\begin{array}{c}13 \\
0.48\end{array}$ & $\begin{array}{l}(2) \\
(0.04)\end{array}$ & $\begin{array}{l}13 \\
0.51\end{array}$ & $\begin{array}{l}(1) \\
(0.02)\end{array}$ & $\begin{array}{l}13 \\
0.50\end{array}$ & $\begin{array}{l}(2) \\
(0.03)\end{array}$ \\
\hline Back & $\lambda_{n}(\mathrm{~m})$ & $\begin{array}{l}15 \\
0.58\end{array}$ & $\begin{array}{l}(3) \\
(0.03)\end{array}$ & $\begin{array}{l}12 \\
0.59\end{array}$ & $\begin{array}{l}(1) \\
(0.06)\end{array}$ & $\begin{array}{c}14 \\
0.58\end{array}$ & $\begin{array}{l}(3) \\
(0.03)\end{array}$ \\
\hline Both & $\begin{array}{l}\hat{\lambda}_{n}(\mathrm{~m}) \\
\zeta\end{array}$ & $\begin{array}{c}14 \\
0.53\end{array}$ & $\begin{array}{l}(3) \\
(0.06)\end{array}$ & $\begin{array}{l}13 \\
0.55\end{array}$ & $\begin{array}{l}(1) \\
(0.04)\end{array}$ & $\begin{array}{l}13 \\
0.54\end{array}$ & $\begin{array}{l}(2) \\
(0.06)\end{array}$ \\
\hline
\end{tabular}

decrease its acceleration. However, the step-down response at low wind speeds is not very well described by Eq. (A5), and the scatter of individual measurements is considerable.

\section{b. Vane tests}

\section{1) Determination of $\lambda_{\mathrm{N}}$ AND $\zeta$}

The author has tested the $\mathrm{k}$ vanes in the wind tunnel of Delft University of Technology, Faculty of Mechanical Engineering and Marine Technology, Laboratory for Aero- and Hydrodynamics. The open working section of this wind tunnel is $0.7 \mathrm{~m}$ in height, $0.9 \mathrm{~m}$ in width, and $1.6 \mathrm{~m}$ long. Vane tests were done with the propellers mounted on the $\mathrm{k}$ vane. At several wind speeds the vane was given a deviation (less than $15^{\circ}$ ) of its equilibrium position and then released. Vane and propeller responses were recorded using a Campbell $21 \mathrm{X}$ datalogger. This procedure was repeated twice for both back and veer wind deviations and for every $\mathrm{k}$ vane used at Cabauw. Special care was given to the symmetry of the experimental setup since some k-vane tests suggested different response characteristics for back and veer wind.

Results are shown in Tables 1 and 2; standard deviations are given in parenthesis. The results have been evaluated by two methods. First, overshoot ratios and the time between successive overshoots have been determined. From Eq. (B6), the damping ratio $\zeta$ can be calculated, and the time between two successive overshoots multiplied by the wind speed equals the halfdamped wavelength $\left(\lambda_{d}\right)$. From this the natural wavelength $\left(\lambda_{n}=\lambda_{d} \sqrt{1-\zeta^{2}}\right)$ can be calculated. Second, Eq. (B2) was fitted to the vane response by a least squares fitting procedure, and from this $\lambda_{n}$ and $\zeta$ were found. As can be seen from Tables 1 and 2, differences for back and veer wind were still found but are not very significant. Not all $\mathrm{k}$ vanes showed stronger damping for back wind deviations; some $\mathrm{k}$ vanes showed equal response for both veer and back wind deviations. From this it can be concluded that asymmetric response is not caused by the wind tunnel but probably by the $\mathrm{k}$ vane itself. However, no satisfactory explanation has been found for it.

\section{2) Torque on the VAne AS Function of ATtACK ANGLE}

The description of vane response as a damped harmonic oscillator is based on the assumption $M=N \beta$, where the torque $M$ increases linearly with the angle of attack $\beta$. The validity of this assumption has been tested in a wind tunnel experiment. A fine cotton wire was attached to the end of the vane arm. Using a pulley and some little weights, a force could be applied to the vane arm. With the wind tunnel running at constant speed more weights were added. This procedure was repeated for two wind tunnel speeds (6.5 and $\left.10.1 \mathrm{~m} \mathrm{~s}^{-1}\right)$ and for two k vanes. Results are shown in Fig. 3. The ordinate is $M / U^{2}$ and the abscissa is $\beta$. Two important features are clear from Fig. 3. First, $M / U^{2}$ does not increase linearly with $\beta$; rather, a parabolic increase seems to fit the data. Second, in veer wind deviations ( $\mathrm{k}$ vane is turned in a back wind direction), $M / U^{2}$ increases faster compared to back wind deviations for these $\mathrm{k}$ vanes. Dynamic tests of the same k vane revealed slightly stronger damping for back wind deviations, which suggests the opposite.

From Fig. 3 it seems there is a little offset in vane response for $\beta>0$. If so, the vane would have an equilibrium position with $\beta \neq 0$. Regression results indicated only insignificant offsets, however. For $\beta<0$

TABLE 2. Model 35301DTX vane properties from wind tunnel tests.

\begin{tabular}{|c|c|c|c|c|c|c|c|}
\hline \multirow[b]{2}{*}{ Veer } & \multirow[b]{2}{*}{$\begin{array}{l}\lambda_{n}(\mathrm{~m}) \\
\zeta\end{array}$} & \multicolumn{2}{|c|}{ Overshoot } & \multicolumn{2}{|c|}{$\begin{array}{l}\text { Least squares } \\
\text { method }\end{array}$} & \multicolumn{2}{|c|}{ Both } \\
\hline & & $\begin{array}{l}11 \\
0.44\end{array}$ & $\begin{array}{l}(2) \\
(0.09)\end{array}$ & $\begin{array}{l}13 \\
0.49\end{array}$ & $\begin{array}{l}(1) \\
(0.09)\end{array}$ & $\begin{array}{l}12 \\
0.46\end{array}$ & $\begin{array}{l}(2) \\
(0.09)\end{array}$ \\
\hline Back & $\begin{array}{l}\lambda_{n}(\mathrm{~m}) \\
\zeta\end{array}$ & $\begin{array}{l}12 \\
0.6\end{array}$ & $\begin{array}{l}(3) \\
(0.1)\end{array}$ & $\begin{array}{l}13 \\
0.58\end{array}$ & $\begin{array}{l}(1) \\
(0.09)\end{array}$ & $\begin{array}{c}12 \\
0.6\end{array}$ & $\begin{array}{l}(2) \\
(0.1)\end{array}$ \\
\hline Both & $\begin{array}{l}\lambda_{n}(\mathrm{~m}) \\
\zeta\end{array}$ & $\begin{array}{c}11 \\
0.5\end{array}$ & $\begin{array}{l}(2) \\
(0.1)\end{array}$ & $\begin{array}{l}13 \\
0.5\end{array}$ & $\begin{array}{l}(2) \\
(0.1)\end{array}$ & $\begin{array}{c}12 \\
0.5\end{array}$ & $\begin{array}{l}(2) \\
(0.1)\end{array}$ \\
\hline
\end{tabular}




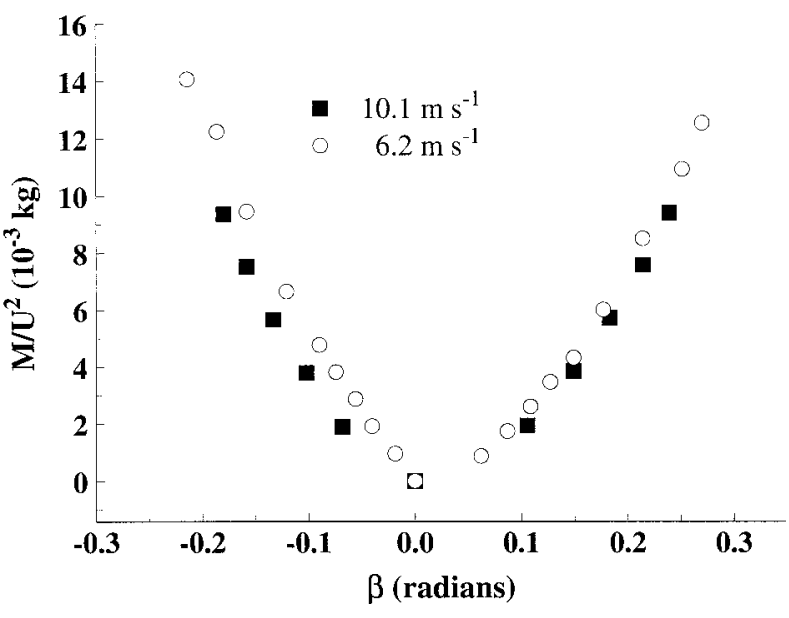

FIG. 3. $M / U^{2}$ as function of $\beta$.

least squares fitting yields $M / U^{2}=-(0.061 \pm 0.004) \beta$; for $\beta>0, M / U^{2}=(0.045 \pm 0.003) \beta$.

\section{3) INFLUENCE OF PROPELLER ROTATION ON VANE DYNAMICS}

To check empirically the theoretical considerations in section $3 \mathrm{~b}$, vane response tests have been repeated with fixed propellers. In spite of the conclusion that no effect could be expected, there was a clear difference in vane response. Both $\lambda_{n}$ and $\zeta$ decreased to 9 (1) $\mathrm{m}$ and 0.43 (0.06), respectively, so the vane is indeed better damped when propellers are rotating. The same effect was observed earlier by Wieringa (1967). Scatter in $\lambda_{n}$ is considerably less when propellers are fixed, especially using the least squares method. In Fig. 4 the difference in response between fixed and rotating propellers can clearly be seen. When propellers are rotating, the vane is usually critically damped after the first overshoot. This behavior cannot be described by Eq. (B2), which assumes equal overshoot ratios for successive overshoots. With propellers fixed the vane behaves much more in agreement with Eq. (B2) so the least squares method will be much more successful.

Flow distortion is certainly different with the propellers fixed than with propellers rotating or removed. The latter experiment was not carried out, unfortunately. It is difficult to understand, however, how flow distortion by the propellers can have such a remarkable effect on the vane dynamics.

\section{Field comparison experiment}

\section{a. Experimental setup}

A field comparison experiment was carried out in June and July 1994 at the meteorological site of WAU. The site has a free fetch of more than 20 obstacle heights in most directions (Bottema 1995). A sonic anemometer (Solent A1012R2, Gill Instruments, United Kingdom)

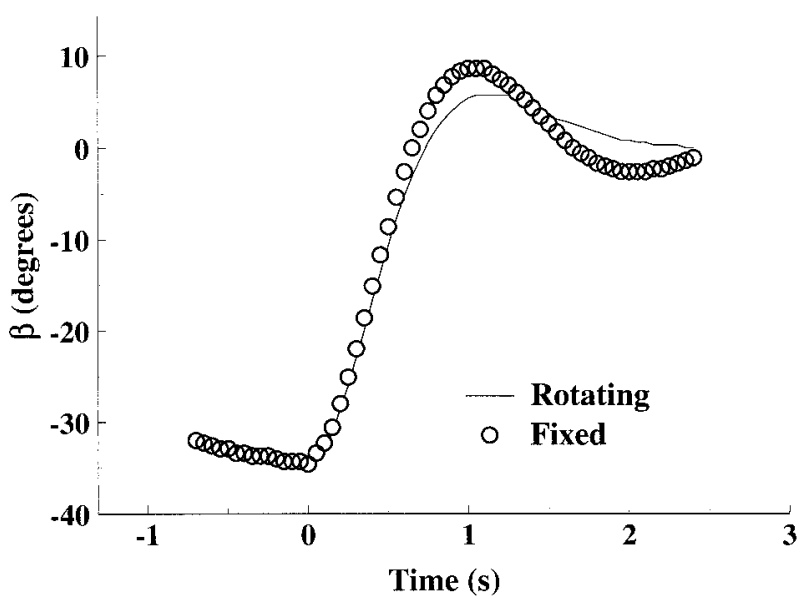

FIG. 4. Influence of rotation propellers on vane response.

was used as reference instrument. The k-vane model 35301 and sonic were place on top of a 20-m mast (diameter $0.15 \mathrm{~m}$, open lattice structure), each on either side of a 1.5-m-long boom. The gap in the potentiometer of the $\mathrm{k}$ vane was oriented toward the sonic $\left(150^{\circ}\right)$. Nearly 30028 -min runs of raw data have been collected at a sampling rate of $10.4 \mathrm{~Hz}$ and spectra were computed. Both the finite response of the sonic as well as the separation between the sensors are insignificant when compared to the distance constant of the $\mathrm{k}$ vane (Bottema 1995).

No instrument is free of error and neither is the Solent sonic anemometer. Flow distortion by the sonic probe may cause an overestimation of $4 \%-6 \%$ in mean wind speed and 20\% in momentum flux, according to Grelle and Lindroth (1994). Mortensen and Højstrup (1995), on the other hand, report a too-low response of the Solent for all wind speed components. However, most effects of flow distortion by the Solent show periodic behavior (period $120^{\circ}$ ). In the data selection used in the present analysis no such periodic effects were found. So the effect of flow distortion by the Solent on the results is expected to be small, and no corrections were applied to the Solent data.

\section{b. Statistical results}

In total $139 \mathrm{~h}$ of data were collected. Situations with weak wind were dominant; only $20 \%$ satisfied $U>4$ $\mathrm{m} \mathrm{s}^{-1}$. About $60 \%$ of the time unstable situations occurred, and almost $65 \%$ of the time the wind did not have a very disturbed fetch. From every 28-min file averages and (co-)variances have been calculated in three approximately 10 -min blocks. No detrending was done. The 28 -min averages of $\overline{v^{\prime}}$ and $\overline{w^{\prime}}$ were rotated to zero. A run was considered stationary when the average total wind speed of all three blocks was within $20 \%$ of the 28-min average. From the total dataset regression coefficients were determined. Results are summarized in Table 3. None of the offset coefficients $\left(c_{0}\right)$ 
TABLE 3. Results from the field comparison experiment. Regression parameters $c_{0}$ and $c_{1}$ from equation $\mathrm{k}$ vane $=c_{0}+c_{1} \times$ sonic; $c_{0}=$ 0 in all cases.

\begin{tabular}{lllll}
\hline \hline & $\Delta c_{0}$ & \multicolumn{1}{c}{$c_{1}$} & \multicolumn{1}{c}{$\Delta c_{1}$} & \multicolumn{1}{c}{$r^{2}$} \\
\hline$U$ & 0.06 & 1.013 & 0.001 & 0.999 \\
$V$ & 0.02 & 0.993 & 0.002 & 0.996 \\
$W$ & 0.02 & 0.95 & 0.01 & 0.92 \\
$\sigma_{u}^{2}$ & 0.11 & $1.011(0.966)$ & 0.003 & 0.99 \\
$\sigma_{v}^{2}$ & 0.06 & 0.998 & 0.004 & 0.99 \\
$\frac{\sigma_{w}^{2}}{u^{\prime} w^{\prime}}$ & 0.02 & 0.769 & 0.004 & 0.98 \\
\hline
\end{tabular}

was significantly different from zero. Therefore, only the uncertainty in $c_{0}\left(\Delta c_{0}\right)$ is given.

The absolute accuracy of wind direction by the vane was not determined since the absolute alignment of both sonic and $\mathrm{k}$ vane is rather difficult. The overall average wind direction difference was put at zero. The standard deviation of all 10-min averages differences equaled $0.8^{\circ}$, so the accuracy of the vane is better than $1^{\circ}$. Large differences in wind direction were restricted to low wind speeds. Maximum differences in the selections $U \geq 1$, 2 , and $4 \mathrm{~m} \mathrm{~s}^{-1}$ were $5^{\circ}, 3^{\circ}$, and $2^{\circ}$, respectively.
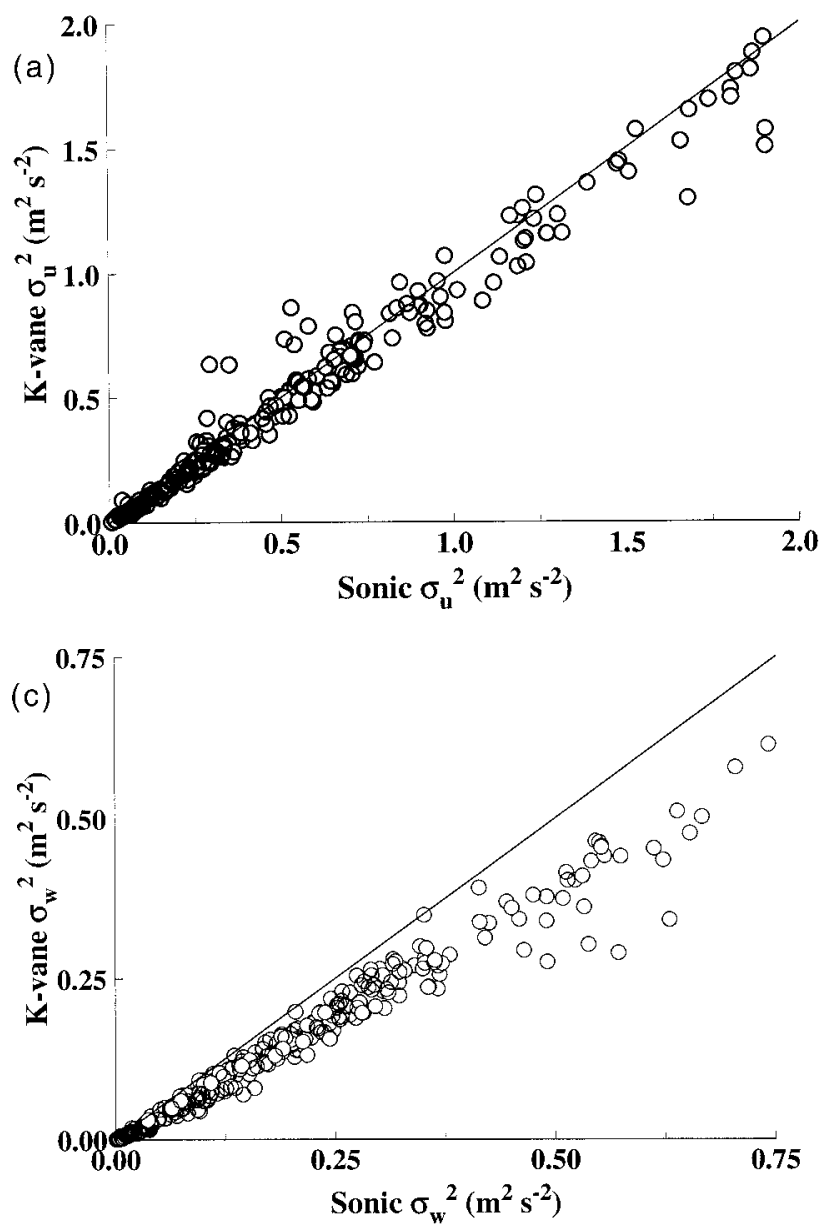

The k-vane-measured $\sigma_{w}^{2}$ and $\overline{u^{\prime} w^{\prime}}$ are less than the sonic-measured values. The highest loss is found for $\sigma_{w}^{2}(-23 \%)$, as can be expected, since the contribution of high frequencies is most dominant in the $w$ spectrum. The k-vane-measured $\sigma_{u}^{2}$ and $\sigma_{v}^{2}$ are not systematically less than the sonic-measured values. This is due to the dominance of low-frequency variance in the $u$ and $v$ variance, for which the $\mathrm{k}$ vane's limited response time is insignificant. Moreover, loss of high-frequency $v$ variance is partially compensated by amplification of variance at the natural wavelength of the vane. The relative high regression coefficients for $\sigma_{u}^{2}$ and $\overline{u^{\prime} w^{\prime}}$ appear to result from a few 10-min blocks with extraordinarily high values. The wind direction from most of these highflux blocks is located in strongly disturbed fetch sectors. When data are selected on stationarity and strongly disturbed wind sectors are excluded, the regression coefficients of $\sigma_{u}^{2}$ and $\overline{u^{\prime} w^{\prime}}$ both decrease with $4 \%$ (see values in parenthesis in Table 3).

Scatterplots of the data selected on wind direction and stationarity are shown in Fig. 5. There seems to be no minimum wind speed to ensure reliable measurements. The selection on stationarity, however, tends to
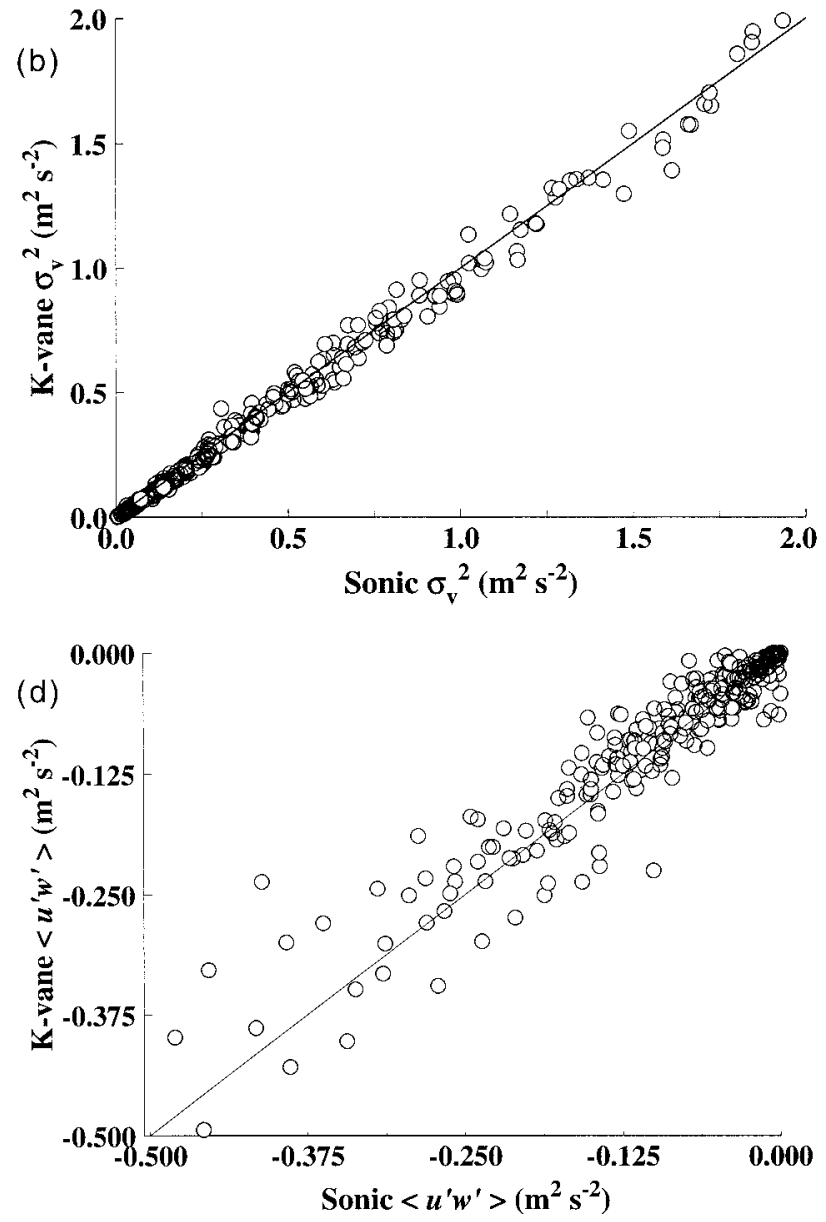

FIG. 5. Comparison of $\sigma_{u}^{2}, \sigma_{v}^{2}, \sigma_{w}^{2}$, and $\overline{u^{\prime} w^{\prime}}$ measured by the $\mathrm{k}$ vane and sonic. Data were selected for stationarity and undisturbed fetch. 


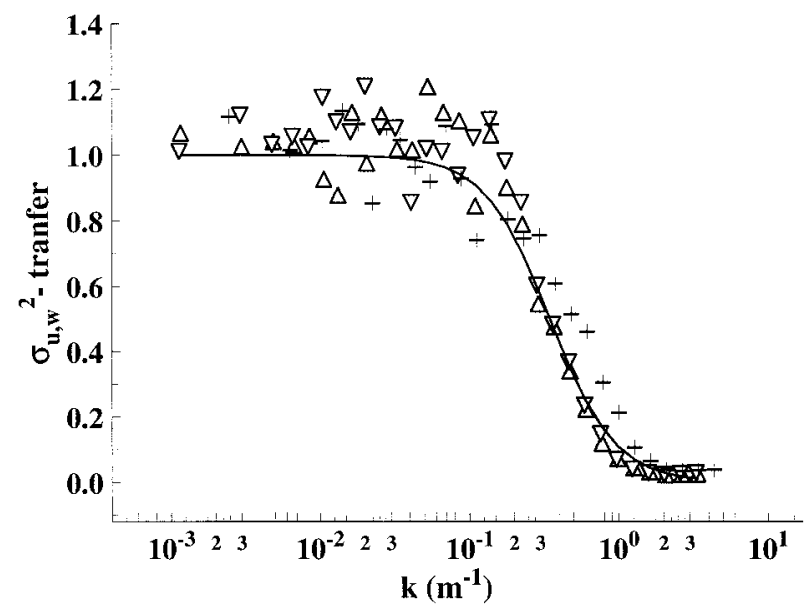

FIG. 6. Measured and fitted transfer functions of $\sigma_{u}^{2}$.

reject low wind speed situations. The minimum wind speed in this selection is $0.3 \mathrm{~m} \mathrm{~s}^{-1}$.

\section{c. Determination of $k$-vane properties from spectra}

After selection of minimum wind speed $\left(2 \mathrm{~m} \mathrm{~s}^{-1}\right)$, stationarity, and wind direction (undisturbed fetch), average $\overline{v^{\prime}}$ and $\overline{w^{\prime}}$ were rotated to zero. No windowing or detrending was done. Spectra were calculated from segments containing $2^{13}$ data points (approximately 13 min) at 20 frequency bands.

Transfer functions can be calculated by dividing the $\mathrm{k}$-vane spectra by the sonic spectra. Transfer of $\sigma_{u}^{2}$, $\sigma_{w}^{2}$, and $\overline{u^{\prime} w^{\prime}}$ are dominated by the propeller dynamics and can be accurately approximated by the simple firstorder equation [Eq. (A6)]. The time "constant" is $D_{45^{\circ}} /$ $U$, where $D_{45^{\circ}}$ is the propeller's distance constant at $45^{\circ}$ angle of attack. The transfer of $\sigma_{v}^{2}$ is dominated by the vane dynamics and can be approximated by a regular second-order equation [Eq. (B3)].

Equations (A6) and (B3) have been fitted using least squares method to the observed transfer functions calculated from the selected data; $D_{45^{\circ}}$ was found to be 2.9 $\mathrm{m}( \pm 0.5 \mathrm{~m}), \lambda_{n}=7.8 \mathrm{~m}( \pm 0.9 \mathrm{~m})$, and $\zeta=\underline{0.49}$ $( \pm 0.05)$. The fitted transfer function of $\sigma_{u}^{2}, \sigma_{w}^{2}$, and $\overline{u^{\prime} w^{\prime}}$ is plotted in Fig. 6 together with the measured transfer functions of $\sigma_{u}^{2}$ for three different runs. In Fig. 7 measured and fitted transfer functions of $\sigma_{v}^{2}$ are plotted.

\section{Evaluation of instrument response errors}

The k-vane overspeeding and the ratio of measured to actual (co-)variances can be estimated from the kvane parameters and spectra of atmospheric turbulence. Standard spectra for stable stratification were taken from Olesen et al. (1984); for unstable stratification, spectra from Højstrup (1982) were used. Cospectra of $\overline{u^{\prime} w^{\prime}}$ were taken from Kaimal et al. (1972). Since the propeller and vane response is faster for higher wind speeds, all errors

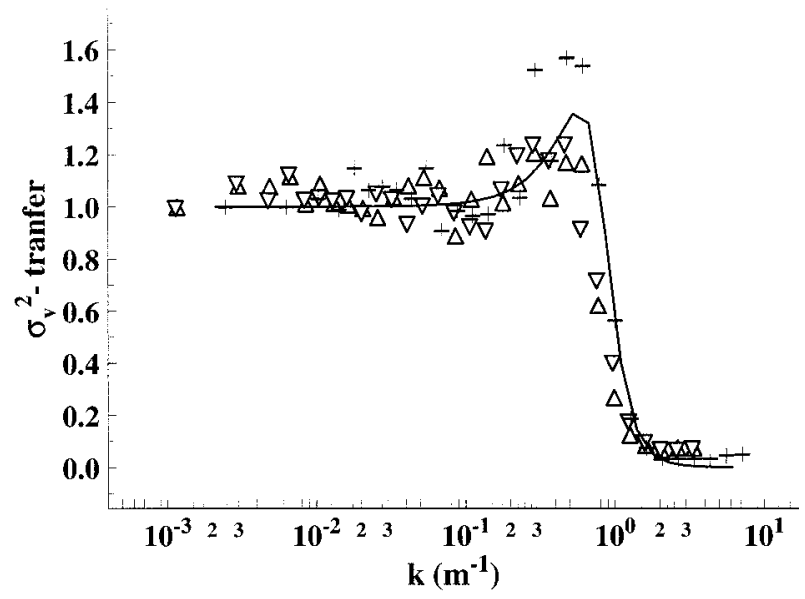

FIG. 7. Measured and fitted transfer functions of $\sigma_{v}^{2}$.

scale with $U$. Wind speed variances in the surface layer, however, scale with $u_{*}$ and the boundary layer height $z_{i}$. To relate $U$ to $u_{*}$ for different heights, the loglinear wind law with stability corrections was used (Garratt 1992, cf. chap. 3). Relations for $\sigma_{u, v, w}$ for unstable stratification were taken from Højstrup (1982), and for stable stratification, values from Kaimal and Finnigan (1994, cf. chap. 2) were adopted. In correspondence to the site at which the $\mathrm{k}$ vanes are used, a roughness length $\left(z_{0}\right)$ of $0.1 \mathrm{~m}$ was taken and $z_{i}$ was set at $1000 \mathrm{~m}$.

\section{a. K-vane overspeeding}

The k-vane parameters derived from the field experiment $\left(D=2.9 \mathrm{~m}, \lambda_{n}=7.8 \mathrm{~m}, \zeta=0.49\right)$ were used to estimate the overspeeding. In Figs. 8 and 9 the total overspeeding is plotted for heights from 10 to $200 \mathrm{~m}$ as a function of stability ( $L$ is Obukhov length). Calculations for stable stratification are only meant for estimation of the order of magnitude of the overspeeding since surface layer scaling does certainly not apply over

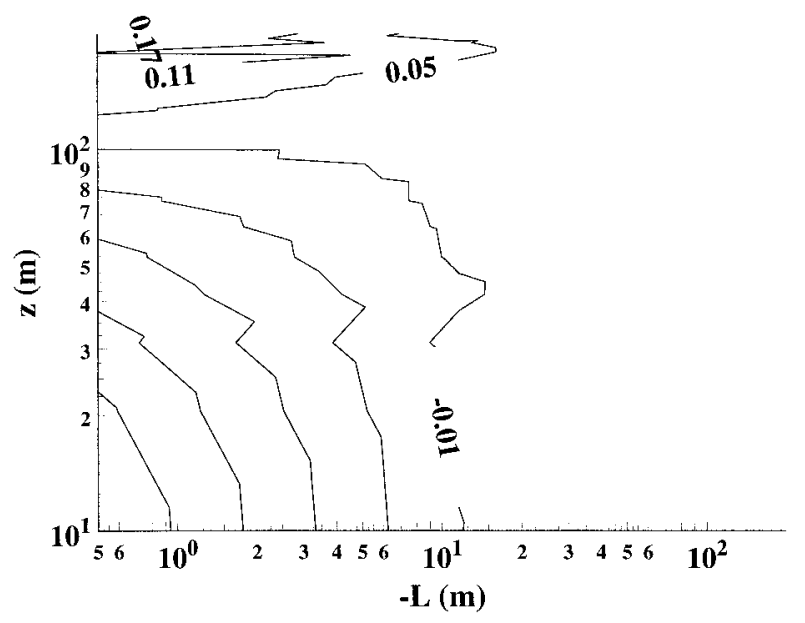

FIG. 8. Overspeeding in unstable stratification. 


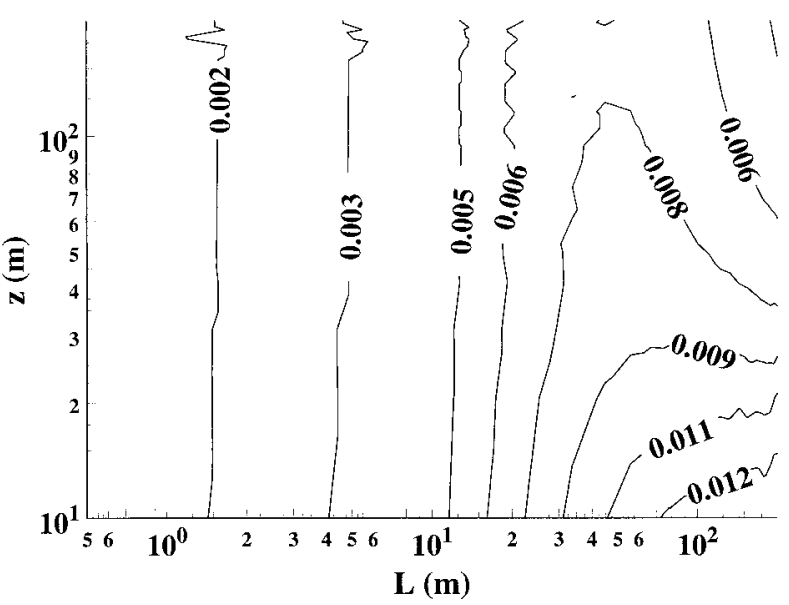

FIG. 9. Overspeeding in stable stratification.

the whole height range in these conditions. Except for very unstable conditions, when the turbulence intensities become very large, $\mathrm{k}$-vane overspeeding or underspeeding is less than a few percent. Note, however, that here again the parameterizations used for the turbulence intensities and spectra are out of their range of validity.

From Eq. (3.26) note that $\bar{\eta}$ usually will be negligible. The integral will obtain values from 0.9 in neutral conditions to 0.98 in very unstable conditions; $\left(u_{*} / U\right)^{2}$ is usually of the order of magnitude $10^{-2}$, so the resulting $w_{m} / U$ will be even one order of magnitude smaller.

\section{b. Correction of variances and momentum flux}

The measured fractions of second-order moments have been estimated by integrating the product of the k-vane transfer functions and the relevant spectra. In Fig. 10 the results are plotted for different values of $z / D$ and $D / L$. Here, $D, \lambda_{n}$, and $\zeta$ were taken from the field experiment, where $z_{i}=1000 \mathrm{~m}$ and $z_{0}=0.1 \mathrm{~m}$. For $\overline{u^{\prime} w^{\prime}}$ (Fig. 11) the spectrum of Moore (1986) is used. It represents an average of the unstable spectra described by Kaimal et al. (1972).

Although $D$ from the field experiments is significantly smaller than that from the wind tunnel tests, the expected loss in (co-)variance is not significantly different when $D_{45^{\circ}}=3 \mathrm{~m} / \sqrt{\cos 45^{\circ}}=3.6 \mathrm{~m}$ is used, which is the result from wind tunnel tests. At 10-m height the difference for $\overline{u^{\prime} w^{\prime}}$ is only $3 \%$, and it becomes even smaller at larger altitudes. Even for $\sigma_{w}^{2}$, which has the highest contribution of high-frequency turbulence, the difference remains smaller than $5 \%$ in nearly neutral conditions. For $\sigma_{u}^{2}$ and $\sigma_{v}^{2}$ differences are smaller than $2 \%$ in all circumstances. So the exact value of $D$ does not seem to be critical at higher altitudes. In fact, the value $z_{i}$, which is hardly ever known, is of the same importance for $\sigma_{u}^{2}$ and $\sigma_{v}^{2}$. When $z_{i}$ values of 500 or $1500 \mathrm{~m}$ are used, differences up to $5 \%$ in the estimated losses are possible.

When $z / L$ and $z_{i}$ are available, the measured variances and momentum flux can be corrected using the estimated losses from the standard spectra. This has been done for the data selected on stationarity and undisturbed fetch. Again regression coefficients were calculated. The results are summarized on the left-hand side of Table 4 . When compared to the results of the uncorrected data (Table 3), it can be seen that part of the lost variances and momentum flux can be restored without increasing scatter.

When standard spectra do not apply, spectra measured by the $\mathrm{k}$ vane itself may be used to correct for loss of variance. Variance spectra can be divided by the appropriate transfer function, and the resulting spectra can be integrated to obtain corrected variances. Integration has to be truncated at the high-frequency end where the signal-to-noise ratio or the transfer function is very low. In this analysis, integration was truncated when the transfer function was below 0.04 . The results are summarized on the right-hand side of Table 4.

Except for $\sigma_{w}^{2}$ the two methods yield comparable results. When standard spectra are used, the corrections for $\sigma_{w}^{2}$ become very large in stable conditions because of the dominance of high-frequency variance. This way noise in the measurements is also amplified. On average, however, this leads to a $c_{1}$ close to 1 but a somewhat lower correlation coefficient. Amplification of noise is explicitly avoided when calculating the correction coefficients from the measured spectra. This may be the reason why the resulting $\sigma_{w}^{2}$ is lower.

\section{Discussion}

\section{a. Minimum wind speed}

The threshold wind speed of a propeller with wellmaintained bearings is of the order of $0.1-0.2 \mathrm{~m} \mathrm{~s}^{-1}$. From the scatterplots (Fig. 5), including many runs with $U$ between 0.3 and $1 \mathrm{~m} \mathrm{~s}^{-1}$, it can be concluded that the minimum wind speed the $\mathrm{k}$ vane needs for reliable measurements is of the same order of magnitude. When bearings wear during long-term field experiments, however, the threshold wind speed will increase and the sensitivity of the propellers will decrease. To exclude any influence of friction at low rotation speed, situations with $U$ below 1-2 $\mathrm{m} \mathrm{s}^{-1}$ should not be considered. Note that the propeller response deviates in the wind tunnel from its regular response when $U$ is below $4 \mathrm{~m} \mathrm{~s}^{-1}$.

\section{b. Bottema's results}

Bottema (1995) tested the k vane's propellers (model 08254) in the wind tunnel of WAU before the field comparison experiment took place. He found the calibration of propellers was in agreement with their pitch and no significant deviations of $k$ from unity [see Eq. (A2)] could be measured. The threshold wind speed $U_{\mathrm{thr}}$ and correction $\Delta U_{f}$ both equaled $0.2 \mathrm{~m} \mathrm{~s}^{-1}$. The best fit of measured cosine response was expressed in gonio- 

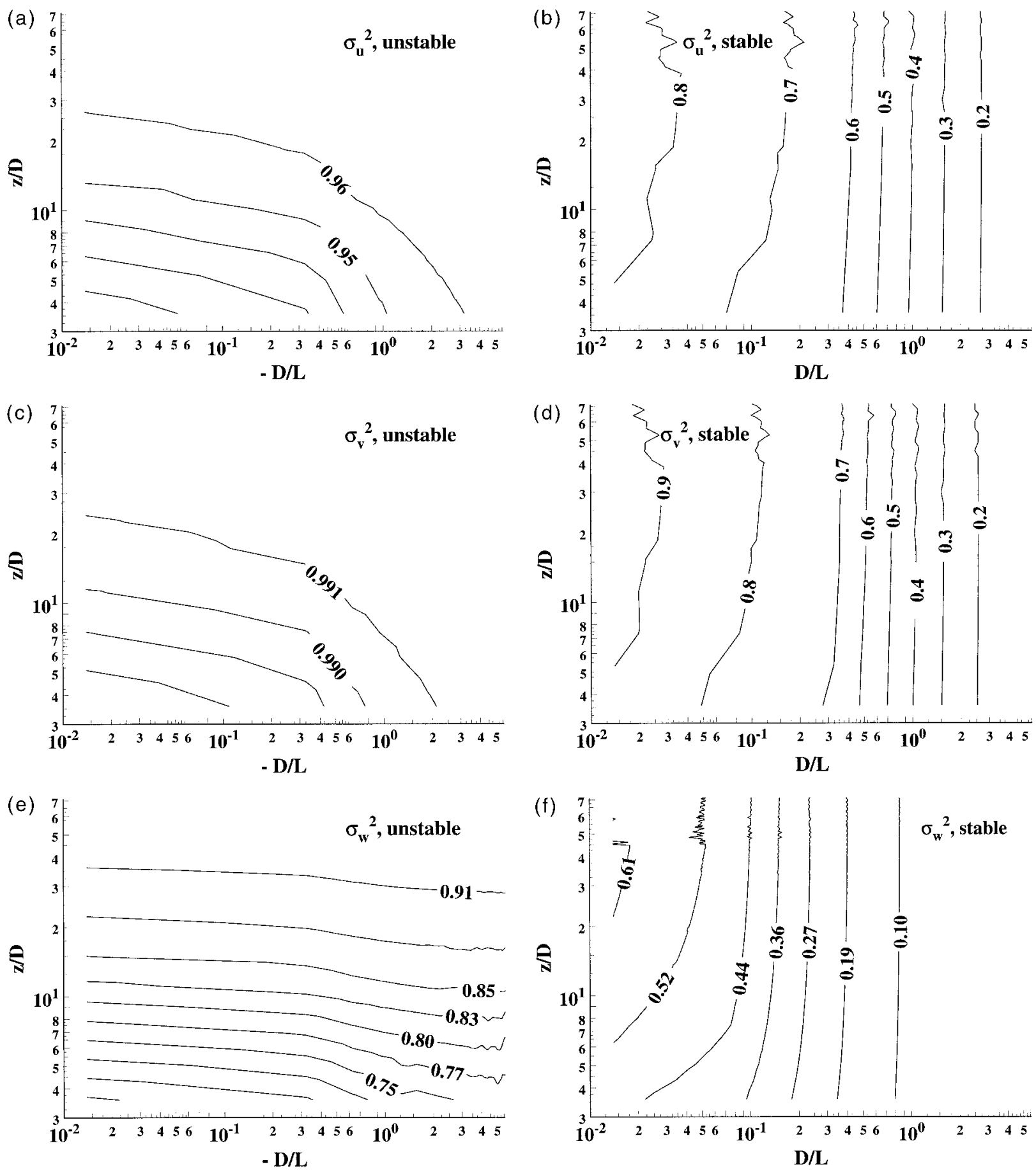

FIG. 10. Measured fractions of $\sigma_{u}^{2}, \sigma_{v}^{2}$, and $\sigma_{w}^{2}$ in stable and unstable conditions estimated from standard spectra.

metric functions, inspired by the expansion formulation in Busch et al. (1980), and was given in Eq. (A4).

Bottema determined the distance constant at $2.5 \mathrm{~m}$ and claims that the dependence on angle of attack agreed with $D(\psi)=D\left(0^{\circ}\right) / \sqrt{\cos \psi}$. From this one would expect $D=2.9 \mathrm{~m}$ for $45^{\circ}$ angle of attack. Bottema, however, reports a value of $3.5 \mathrm{~m}$ for $D_{45^{\circ}}$. For large wind speed drops, he reports a faster propeller response. These step-down tests were performed by poor-man methods such as quickly opening the wind tunnel door or by speeding up the propeller by motor and $\mathrm{V}$ belt and then suddenly pushing the belt away.

Because of the size of the $\mathrm{k}$ vane (length of arm and blade $0.7 \mathrm{~m}$, working section wind tunnel $0.40 \mathrm{~m} \times$ 


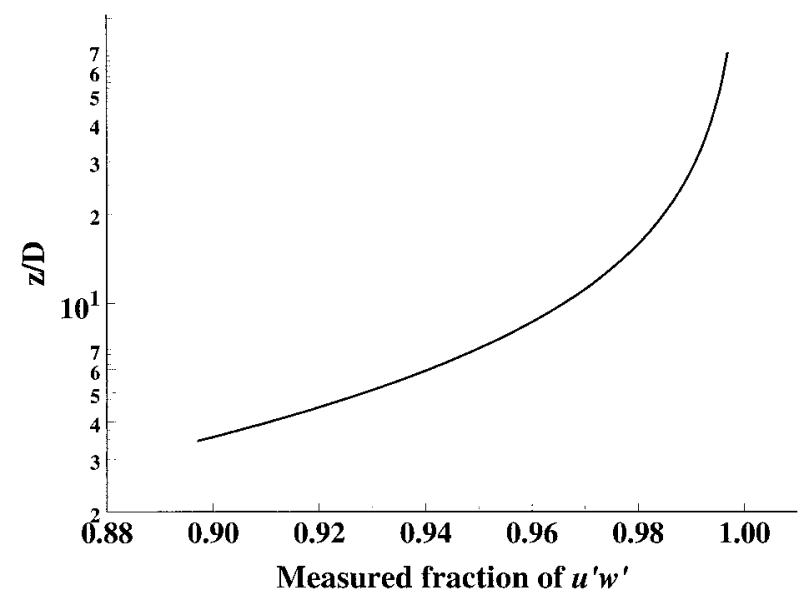

FIG. 11. Measured fraction of $\overline{u^{\prime} w^{\prime}}$ calculated from literature spectra for unstable conditions.

$0.40 \mathrm{~m}$ ), vane tests could hardly be done in the WAU wind tunnel. For want of something better, Bottema still evaluated vane properties from experiments in this wind tunnel. His reported values of the natural wavelength $\lambda_{n}$ and the damping ratio $\zeta$ vary considerably with wind speed. Bottema argues that the most reliable estimates of $\lambda_{n}$ and $\zeta$ were made at low wind speeds because of undesirable oscillation phenomena at high wind speeds. At $U=2 \mathrm{~m} \mathrm{~s}^{-1}$ he found $\lambda_{n}=4 \mathrm{~m}$ and $\zeta=0.4$.

\section{c. Propeller response at low wind speeds}

The smaller $D$ for both step-up and step-down changes (Fig. 2) can be the result of the size of the step change. Doing tests at low wind speeds usually means applying small wind speed changes as well, especially for the step-down tests. Hicks (1972) found that "the time required for a propeller to respond to sudden increases in wind speed increases with the magnitude of the fluctuation." In other words, at low wind speeds, applying small wind speed changes, the propeller responds quicker.

This also explains the smaller $D$ and larger $D_{45^{\circ}}$ found by Bottema. He used wind tunnel speeds of 2, 4, and $6 \mathrm{~m} \mathrm{~s}^{-1}$ when doing step response tests and found a $D$ of 2.4, 2.7, and 2.8, respectively (M. Bottema 1997, personal communication). This is in close agreement with Fig. 2. The reported average value for $D$ is biased because the wind speeds used were too low. Since the propeller response is less when it is inclined to the flow, Bottema probably used a larger wind tunnel speed when assessing $D_{45^{\circ}}$. The resulting response length will be larger because of this larger wind tunnel speed.

The faster propeller response for wind speed decreases compared to wind speed increases will reduce the overspeeding of the propeller. If the difference between step-up and step-down response times as well as the magnitude of the wind speed fluctuations was to be large, the step-down response time could even be smaller than for a step-up time. In that case the propeller could underspeed.

\section{d. Field versus laboratory response}

For both propeller and vane it seems that the field response is faster than the tunnel response, resulting in a smaller $D$ and $\lambda_{n}$. For the propellers discussed in this report $D=3.0 \mathrm{~m}$ (wind tunnel) and $D_{45^{\circ}}=2.9 \mathrm{~m}$ (field experiment), which do not correspond at all to the observed increase of $D$ with angle of attack. The parameters found for the vane are $\lambda_{n}=7.8 \mathrm{~m}, \zeta=0.49$ (field comparison) and $\lambda_{n}=13 \mathrm{~m}, \zeta=0.54$ (wind tunnel). A reason for the difference may be that the wind tunnel used is too small for the present propellers. However, other researchers also found a faster response in the field than in the laboratory (Fichtl and Kumar 1974; Pond et al. 1979). Because in a turbulent wind field there are no step changes, the propeller will usually be closer to its equilibrium response. Hicks' (1972) results suggest that the faster field response may be caused by the smaller wind speed changes that are applied. On the contrary, Horst (1973) explained a larger $D$ found from field experiments as the result of the increase of $D$ with angle of attack. Since the field comparison results show less scatter and the field performance is thought to be of major importance, the author recommends using these results only when assessing instrument response parameters.

Katsaros et al. (1993) obtained propeller and vane parameters from laboratory tests. The natural wavelength and damping ratio they reported compare well to those found from our field comparison experiment. The vane they used, however, had slightly different dimensions. The distance constant they reported $(2.2 \mathrm{~m})$ is small. From their report it is not clear whether this is the distance constant at $0^{\circ}$ angle of attack. If so, $D_{45^{\circ}}$

TABLE 4. Regression parameters for the corrected data. Spectra were taken from literature (left-hand side) or spectra measured by the $\mathrm{k}$ vane itself were used (right-hand side).

\begin{tabular}{|c|c|c|c|c|c|c|c|c|}
\hline & \multicolumn{4}{|c|}{ Standard spectra } & \multicolumn{4}{|c|}{ Measured spectra } \\
\hline & $\Delta c_{0}$ & $c_{1}$ & $\Delta c_{1}$ & $r^{2}$ & $\Delta c_{0}$ & $c_{1}$ & $\Delta c_{1}$ & $r^{2}$ \\
\hline$\overline{\sigma_{u}^{2}}$ & 0.09 & 1.038 & 0.009 & 0.98 & 0.06 & 1.017 & 0.005 & 0.992 \\
\hline$\sigma_{v}^{2}$ & 0.06 & 1.010 & 0.007 & 0.99 & 0.05 & 1.002 & 0.005 & 0.992 \\
\hline$\sigma_{w}^{2}$ & 0.05 & 1.03 & 0.01 & 0.95 & 0.02 & 0.930 & 0.007 & 0.98 \\
\hline$\frac{w}{u^{\prime} w^{\prime}}$ & 0.03 & 0.96 & 0.02 & 0.90 & 0.03 & 0.94 & 0.02 & 0.87 \\
\hline
\end{tabular}


is approximately $2.6 \mathrm{~m}$, which is close to the value of $2.9 \mathrm{~m}$ found from the field comparison experiment.

\section{e. Simple methods for the estimation of vane parameters}

For simple vanes Wieringa (1967) derived formulas to estimate their dynamic parameters from the dimensions and weight of the vane (see appendix B). For the $\mathrm{k}$ vane $S=0.094 \mathrm{~m}^{2}$ (area of the vane blade), $r_{v}=$ $0.48 \mathrm{~m}$ (distance from the vane pivot to one-quarter of the blade chord), and $J_{\text {old }}=0.086 \mathrm{~kg} \mathrm{~m}^{2}$ (moment of inertia of the vane). The latter has been assessed by attaching a little weight on the vane and then measuring the period of oscillation. This experiment has been repeated for several weights at different distances from the pivot of the vane. To reduce damping by the vane, the blade was twisted $90^{\circ}$.

When an infinite aspect ratio is assumed, the torque parameter $a_{v}$ equals $2 \pi$, where $N / U^{2}=0.18 \mathrm{~kg}, \lambda_{n}=$ $4.4 \mathrm{~m}$, and $\zeta=0.34$. These values compare rather well with the values Bottema (1995) found $\left(N / U^{2}=0.16 \mathrm{~kg}\right.$, $\lambda_{n}=4 \mathrm{~m}$, and $\zeta=0.4$ at $U=2 \mathrm{~m} \mathrm{~s}^{-1}$ ). Since the blade of the $\mathrm{k}$ vane approximates a square, the aspect ratio is not infinite. In fact, $a_{v}=2.0$ (span of the vane blade $b$ $=0.36 \mathrm{~m}$ ). In that case $\lambda_{n}$ and $\zeta$ should equal $6.0 \mathrm{~m}$ and 0.25 , respectively. When using the results of section $4 \mathrm{~b}$ on the torque on the vane as function of angle of attack, $\lambda_{n}=8 \mathrm{~m}$ and $\zeta=0.2$.

The presence of the propellers and their mounting can certainly not be neglected in case of the $\mathrm{k}$ vanes. The presence of surface before the pivot of the vane will increase $\lambda_{n}$ as well as $\zeta$. The area of the projection of the surface before the pivot on a vertical plane $S_{w}$ is estimated at $0.02 \mathrm{~m}^{2}$, and the distance of the aerodynamic center to the vertical axis $r_{w}$ is $0.2 \mathrm{~m}$. This results in an increase of almost 5\% in $\lambda_{n}$ and of $9 \%$ in $\zeta$ (Wieringa and van Lindert 1971).

These formulas apply to simple vanes, however. The shape of the propellers and their mounting does not resemble that of a vane. This may explain the large difference, especially in $\zeta$, between the estimated vane parameters and the measured parameters.

\section{Conclusions}

From the field experiment it can be concluded that the $\mathrm{k}$ vane's measurements of average wind speed and direction are very accurate. Overspeeding or artificial vertical wind speed will generally be very small. Overspeeding could be significant in conditions of very high instability. These occasions usually are accompanied by very low wind speeds. Then the correction $\Delta u_{f}$, which is usually neglected, and the different propeller response at these wind speeds may mask any overspeeding.

Both perturbation theory and a field comparison experiment show that the $\mathrm{k}$ vane behaves as a first-order sensor. The only relevant instrument parameter for measured variances and fluxes is $D_{45^{\circ}}$, the response length at $45^{\circ}$ angle of attack ( $2.9 \mathrm{~m}$ for the 35301 model). This parameter can best be determined from a field comparison experiment, not from wind tunnel tests. Wind tunnel tests show much scatter, and the resulting parameters do not correspond very well to those from the field comparison experiment. When used above 20-m height, however, the exact value of $D_{45^{\circ}}$ is of insignificant importance.

Transfer functions of the (co-)variances can be described by the regular first-order [Eq. (A6), $\sigma_{u}^{2}, \sigma_{w}^{2}$, and $\left.\overline{u^{\prime} w^{\prime}}\right]$ or second-order [Eq. (B3), $\sigma_{v}^{2}$ ] equations. These transfer functions together with standard spectra can be used to estimate the loss of (co-)variance. To do so a stability parameter and boundary layer height are necessary. After this correction the velocity variances correspond well to those measured by a sonic anemometer. In very stable conditions the corrections may become large, increasing scatter in the corrected results.

Instead of standard spectra, spectra measured by the $\mathrm{k}$ vane itself can be used to calculate corrections for the measured (co-)variances. In that case no information on atmospheric conditions is necessary. Using this method high-frequency variance may not be fully restored, resulting in lower estimates of $\sigma_{w}^{2}$. On average both methods yield fluxes and variances that are correct within $10 \%$.

Acknowledgments. The author would like to thank Prof. Jon Wieringa for setting up this project and for good advice at various stages while writing this paper. The author would also like to thank Dr. Marcel Bottema, who prepared and started the field comparison experiment. Arjan van Dijk from the Delft University of Technology helped me doing the wind tunnel tests at his department. In carrying out the experiments many of the technical staff of the meteorology department of WAU were of great help. I would like to especially mention Bert Heusinkveld and Frits Antonysen. Also many thanks to Fred Bosveld from the KNMI, members of the meteorology department of WAU, and the reviewers who carefully read the manuscript and gave lots of valuable comments.

The investigations were (in part) supported by the Netherlands Geosciences Foundation (GOA) with financial aid from the Netherlands Organisation for Scientific Research (NWO), Project No. 750.194.15.

\section{APPENDIX A}

\section{Propeller Dynamics}

The $\mathrm{k}$ vane is provided with four-bladed Gill propellers (Gill 1975). The propellers are helicoidally shaped, that is, the angle between the blade chords and the propeller plane is

$$
\alpha_{b}=\arctan \left(\gamma_{R} R / r\right),
$$


where $\gamma_{R}$ is the pitch factor, $R$ is the radius of the propeller, and $r$ is the distance to the propeller axis (Busch et al. 1980). In absence of drag and friction, the ratio of the wind speed to the orbital speed of the propeller tips $U / \omega R$ equals $\gamma_{R}$. In this case the angle of attack of the relative wind on the propeller blade will be zero. Then the pitch, the length of the column of air that has passed the propeller after one revolution, equals $2 \pi \gamma_{R} R$. In practice $\omega R$ will be less than $U / \gamma_{R}$ by a factor $k$. Inclusion of a correction $\left(\Delta u_{f}\right)$ for wind speed independent friction results in the calibration equation for the propeller

$$
U=\gamma_{R} k R \omega+\Delta u_{f} .
$$

Note that in this equation, equal to Eq. (43) from Busch et al. (1980), $k$ will be larger than 1 in order to reduce $\omega$ at given wind speed $U$. Usually $k$ is very close to unity (within $1 \%$ ) and $\Delta u_{f}$ is very small (less than $0.1 \mathrm{~m} \mathrm{~s}^{-1}$ ). The correction $\Delta u_{f}$ should not be confused with the starting or threshold wind speed $U_{\text {thr }}$. The former is an offset to be determined from regression of the calibration curve; the latter is the minimum wind speed required to start the propeller from rest. Usually $U_{\mathrm{thr}}$ is larger than $\Delta u_{f}$.

When inclined to the wind direction, the propeller response is less than the wind speed component parallel to the propeller axis since propellers exhibit imperfect cosine response (Drinkrow 1972; Hicks 1972; Horst 1973). The actual angular response can be written as

$$
C(\Psi) \cos \Psi=\left(\gamma_{R} k R \omega+\Delta u_{f}\right) / \mathrm{U} .
$$

To correct propeller response for imperfect cosine response, $C(\Psi)$ has to be measured in a wind tunnel. For the propellers used in this experiment (no. 08254, $20 \mathrm{~cm} \times 30 \mathrm{~cm}), C(\Psi)$ is in close agreement with

$$
C(\Psi)=1-0.3 \sin ^{2}(\Psi)+0.02 \sin (6 \Psi),
$$

taken from Bottema (1995). When a propeller mounted on a vane is placed in a turbulent wind field, it will generally not be aligned perfectly into the instantaneous wind direction. Since usually $C(\Psi) \leq 1$ for propellers, its response will be reduced due to lateral and vertical wind fluctuations, even though the total wind vector is larger. The corresponding errors were called the $v$ - and $\omega$-error by MacCready (1966).

The propeller response to a step change in wind speed from $U_{0}$ to $U_{\infty}$ can be described by a first-order differential equation (MacCready and Jex 1964):

$$
\partial U_{\text {prop }} / \partial t=\left[U_{\infty}-U_{\text {prop }}(t)\right] / \tau, \quad \tau=D / U_{\infty} \text {. (A }
$$

The corresponding transfer function for wind speed variance is given by

$$
T_{u}=\left(1+\tau^{2} \omega^{2}\right)^{-1} .
$$

Here $D$ is called the distance constant because it is assumed to be independent of wind speed. Since $\tau$ is smaller for larger wind speeds, the propeller responds faster to increasing wind speed and slower to decreasing wind speed. Placing the propeller in a turbulent wind field will cause the propeller to overspeed. The magnitude of the overspeeding will increase with $D$. This feature is similar to cup anemometer overspeeding and has been discussed in detail by Busch and Kristensen (1976). MacCready (1966) called this the $u$-error of a propeller anemometer. Here $D=U_{\infty} \tau$ increases slightly as the angle $\Psi$ between wind direction and propeller axis increases. Note that this is only true when $U$ is equal to the total wind, not to the component parallel to the propeller axis [compare Busch et al. (1980) and Bottema (1995)].

For the propeller blades to act as airfoils, the angle of attack of the relative wind should not exceed $15^{\circ}$. This restriction is expressed by the following relation:

$$
\omega_{\min }^{\max } / \omega_{0}=R_{R} / r \tan \left(\alpha_{b} \mp 15^{\circ}\right),
$$

where $\omega_{0}$ is the equilibrium angular velocity of the propeller. For the propellers used with the $\mathrm{k}$ vane $\left(R_{R}=\right.$ $0.3 / 2 \pi \mathrm{m}), \omega_{\min } / \omega_{0}=0.6$, and $\omega_{\max } / \omega_{0}=1.7$. This means that when step-up responses are used to determine $D$, only the part after $60 \%$ adaption, the tail, should be used. Note from Eq. (A7) that if $\omega \neq \omega_{0}$, the angle of attack is a function of $r$.

\section{APPENDIX B}

\section{Vane Dynamics}

The vane is often assumed to be a damped harmonic oscillator (Busch et al. 1980; Wieringa 1967). This assumption is only valid if wind torque $M$ on the vane increases linearly with attack angle $\beta: M=N \beta$. In absence of friction, the vane equation can be written as

$$
-J \frac{\partial^{2} \beta}{\partial t^{2}}=N \beta+\left(\frac{r_{v} N}{U}\right) \frac{\partial \beta}{\partial t} .
$$

Here $J$ is the moment of inertia of the vane and $r_{v}$ the distance from the aerodynamic center of the vane blade to the pivot of the vane. The term in parenthesis in Eq. (B1) is the aerodynamic damping. Any friction that is proportional to $U^{-1} \partial \beta / \partial t$ can simply be added to the aerodynamic damping (Wieringa 1967). The solution to Eq. (B1) for a subcritically damped vane $(\zeta<$ 1) is

$$
\beta=\beta_{0} \exp (-\gamma t-i \omega t)
$$

where $\gamma=\zeta \omega_{0}, \omega_{0}=(N / J)^{1 / 2}, \zeta=r_{v} \omega_{0} / 2 U, \omega^{2}=$ $\omega_{0}^{2}\left(1-\zeta^{2}\right)$, and $\beta_{0}=\beta\left(t_{0}\right)$. The equilibrium value of $\beta$ is $0, \lambda_{n}=2 \pi U / \omega_{0}$ is the natural wavelength, and $\zeta$ is the damping ratio. Friction that is not proportional to $U^{-1} \partial \beta / \partial t$ will cause $\zeta$ to be a function of $U$ (Busch et al. 1980). If $M$ is not linearly proportional to $\beta$, the zeroth and first derivative of $\beta$ mix up and a nonlinear differential equation results.

The transfer function for wind direction variance is given by 


$$
T_{v}=\left[\left(1-\omega^{2} / \omega_{0}^{2}\right)^{2}+\left(2 \zeta \omega / \omega_{0}\right)^{2}\right]^{-1} .
$$

So the measured wind direction variance and the covariances between real and measured wind direction are given by

$$
\begin{gathered}
\sigma_{\beta}^{2}=\overline{\beta^{\prime 2}}=\left(\sigma_{v} / U\right)^{2} \int_{0}^{\infty} T_{v} S_{v}(\omega) d \omega, \\
\overline{\beta^{\prime} \phi^{\prime}}=\left(\sigma_{v} / U\right)^{2} \int_{0}^{\infty}\left(1-\omega^{2} / \omega_{0}^{2}\right) T_{v} S_{v}(\omega) d \omega .
\end{gathered}
$$

A subcritically damped vane overshoots. The ratio of two successive overshoots equals

$$
h=\beta_{i} / \beta_{i-1}=\exp \left[-\pi \zeta /\left(1-\zeta^{2}\right)^{1 / 2}\right]
$$

Experimentally $\omega$ and $\gamma$ or $\zeta$ can be found by fitting Eq. (B2) to the measured response or by measuring successive overshoots and the time between them.

Vane parameters $\lambda_{n}$ and $\zeta$ can also be calculated from the dimensions and weight of the vane (Wieringa 1967):

$$
\lambda_{n}=2 \pi\left(J U^{2} / N\right)^{1 / 2}, \quad \zeta=\pi r_{v} / \lambda_{n} .
$$

Here $N$ can be estimated from the area of the vane blade $S$, the torque parameter $a_{v}$, and $r_{v}$ :

$$
N / U^{2}=r_{v} F_{v} / \beta U^{2}=\rho a_{v} S / 2,
$$

where $F_{v}$ is the force on the vane blade. The torque parameter is given by

$$
a_{v}=c_{v} / \beta=c_{v_{0}} A / \beta(A E+2), \quad A=b^{2} / S,
$$

where $b$ is the span of the vane blade, $A$ is the aspect ratio, and $c_{v_{0}}$ is the lift force coefficient for infinite aspect ratio. Here $E$ is the edge correction and equals the ratio of the semiperimeter to the vane span. When infinite aspect ratio is assumed, $a_{v}=2 \pi$.

\section{REFERENCES}

Ataktürk, S. S., and K. B. Katsaros, 1987: Intrinsic frequency spectra of short gravity-capillary waves obtained from temporal measurements of wave height on a lake. J. Geophys. Res., 92, 51315141.

_ and _ 1989: The K-Gill: A twin propeller-vane anemometer for measurements of atmospheric turbulence. J. Atmos. Oceanic Technol., 6, 509-515.

Bottema, M., 1995: Calibration study of the K-Gill propeller vane. Tech. Rep. TR-181, KNMI, De Bilt, the Netherlands, 46 pp.

Busch, N. E., and L. Kristensen, 1976: Cup anemometer overspeeding. J. Appl. Meteor., 15, 1328-1332.

- - O. Christensen, L. Kristensen, L. Lading, and S. E. Larsen, 1980: Cups, vanes, propellers and laser anemometers. Air-Sea Interaction: Instruments and Methods, F. Dobson, L. Hasse, and R. Davids, Eds., Plenum, 11-46.

Desjardins, R. L., W. S. Reid, D. J. Buckley, and W. Fagan, 1986 Description and performance testing of a low friction, twinpropeller anemometer with wind vane. J. Phys. E: Sci. Instrum., 19, 632-637.

Drinkrow, R., 1972: A solution to the paired Gill-anemometer response function. J. Appl. Meteor., 11, 76-80.

Fichtl, G. H., and P. Kumar, 1974: The response of a propeller an- emometer to turbulent flow with the mean wind direction perpendicular to the axis of rotation. Bound.-Layer Meteor., 6, 363379 .

Garratt, J. R., 1992: The Atmospheric Boundary Layer. Cambridge University Press, $316 \mathrm{pp}$.

Gill, G. C., 1975: Development and use of the Gill UVW anemometer. Bound.-Layer Meteor., 8, 475-495.

Grelle, A., and A. Lindroth, 1994: Flow distortion by a Solent sonic anemometer: Wind tunnel calibration and its assessment for flux measurements over forest and field. J. Atmos. Oceanic Technol., 11, 1529-1542.

Hicks, B. B., 1972: Propeller anemometers as sensors of atmospheric turbulence. Bound.-Layer Meteor., 3, 214-228.

Højstrup, J., 1982: Velocity spectra in the unstable planetary boundary layer. J. Atmos. Sci., 39, 2239-2248.

Horst, T. W., 1973: Corrections for response errors in a three-component propeller anemometer. J. Appl. Meteor., 12, 716-725.

Kaimal, J. C., and J. J. Finnigan, 1994: Atmospheric Boundary Layer Flows-Their Structure and Measurement. Oxford University Press, 289 pp.

— J. C. Wyngaard, Y. Izumi, and O. R. Coté, 1972: Spectra characteristics of surface-layer turbulence. Quart. J. Roy. Meteor. Soc., 98, 563-589.

Katsaros, K. B., S. D. Smith, and W. A. Oost, 1987: HEXOSHumidity Exchange Over Sea. A program for research on watervapor and droplet fluxes from sea to air at moderate to high wind speeds. Bull. Amer. Meteor. Soc., 69, 466-476.

—, M. A. Donelan, and W. M. Drennan, 1993: Flux measurements from a SWATH ship in SWADE. J. Mar. Sys., 4, 117-132.

Large, W. G., and S. Pond, 1981: Open ocean momentum flux measurements in moderate to strong winds. J. Phys. Oceanogr., 11, 324-336.

— , and — 1982: Sensible and latent heat flux measurements over the ocean. J. Phys. Oceanogr., 12, 464-482.

MacCready, P. B., 1966: Mean wind speed measurements in turbulence. J. Appl. Meteor., 5, 219-225.

, and H. R. Jex, 1964: Response characteristics and meteorological utilization of propeller and vane wind sensors. J. Appl. Meteor., 3, 182-193.

Monna, W. A. A., 1983: The KNMI wind tunnel (in Dutch). Tech. Rep. TR-32, KNMI, De Bilt, the Netherlands, 34 pp.

Moore, C. J., 1986: Frequency response corrections for eddy correlation systems. Bound.-Layer Meteor., 37, 17-35.

Mortensen, N. G., and J. Højstrup, 1995: The Solent sonic-response and associated errors. Preprints, Ninth Symp. on Meteorological Observation and Instrumentation, Charlotte, NC, Amer. Meteor. Soc., 501-506.

Olesen, H. R., S. E. Larsen, and J. Højstrup, 1984: Modelling velocity spectra in the lower part of the planetary boundary layer. Bound.Layer Meteor., 29, 285-312.

Pond, S., W. G. Large, M. Miyake, and R. W. Burling, 1979: A Gill propeller-vane anemometer for flux measurements during moderate and strong winds. Bound.-Layer Meteor., 16, 351-364.

van Ulden, A. P., and J. Wieringa, 1996: Atmospheric boundary layer research at Cabauw. Bound.-Layer Meteor., 78, 39-69.

Verkaik, J. W., 1997: Wind profiles and momentum fluxes in the lower neutral PBL over flat heterogeneous terrain. Preprints, 12th Symp. on Boundary Layers and Turbulence, Vancouver, BC, Canada, Amer. Meteor. Soc., 546-547.

Wieringa, J., 1967: Evaluation and design of wind vanes. J. Appl. Meteor., 6, 1114-1122.

_ and F. X. C. M. van Lindert, 1971: Application limits of doublefin and coupled wind vanes. J. Appl. Meteor., 10, 137-145.

Wyngaard, J. C., 1981: Cup, propeller, vane, and sonic anemometers in turbulence research. Аnпи. Rev. Fluid Mech., 13, 399-423.

Zhang, S. F., 1988: A critical evaluation of the von Kármán constant from a new atmospheric surface layer experiment. Ph.D. thesis, University of Washington, $133 \mathrm{pp}$. [Available from University Microfilms, 300 North Zeeb Rd., Ann Arbor, MI 48106.] 